\title{
Lycii radicis cortex inhibits glucocorticoid-induced bone loss by downregulating Runx2 and BMP-2 expression
}

\author{
BINA LEE, SOOYEON HONG, MINSUN KIM, EUN-YOUNG KIM, HI-JOON PARK, \\ HYUK-SANG JUNG, JAE-HYUN KIM and YOUNGJOO SOHN
}

Department of Anatomy, College of Korean Medicine, Kyung Hee University, Seoul 02-447, Republic of Korea

Received February 4, 2021; Accepted June 1, 2021

DOI: $10.3892 / \mathrm{ijmm} .2021 .4988$

\begin{abstract}
Lycii radicis cortex (LRC) has been used to regulate high blood pressure, body temperature, pain and bone disorders in East Asia. Glucocorticoids (GCs), also known as steroids, are potent immunity regulators widely used in the treatment of inflammatory diseases. However, despite their effectiveness, GC usage is strictly controlled due to severe side-effects, such as osteoporosis. However, further research is required as to date, at least to the best of our knowledge, there is no appropriate model to overcome secondary osteoporosis as a side-effect of GC use. Thus, the aim of the present study was to establish an experimental model of osteoporosis induced by GC. Furthermore, the present study aimed to establish the research methodology for medical evaluations of the effectiveness and side-effects of GCs. A secondary osteoporosis animal model was established, and the animals were divided into two groups as follows: The allergic contact dermatitis (ACD)-induced group and the non-ACD-induced group. In the ACD-induced group, a GC topical application group was compared with a GC subcutaneous injection group. The results revealed that the presence of ACD affected the induction of GC-mediated osteoporosis. Therefore, the group exhibiting induced ACD that was treated with a topical application of GC was selected for examining the side-effects of GCs. The effects of LRC on secondary osteoporosis were confirmed in vivo and in vitro. The results indicated that LRC regulated dexamethasone-induced osteoblast apoptotic markers, including caspase- 6 , caspase- $9, \mathrm{X}$-linked inhibitor of apoptosis, apoptosis inhibitor 1 and apoptosis inhibitor 2, and increased the expression of osteoblast differentiation-related genes, such as Runt-related transcription factor 2 and bone
\end{abstract}

Correspondence to: Professor Youngjoo Sohn or Dr Jae-Hyun Kim, Department of Anatomy, College of Korean Medicine, Kyung Hee University, 26-6 Kyungheedae-ro, Dongdaemun-gu, Seoul 02-447, Republic of Korea

E-mail: youngjoos@khu.ac.kr

E-mail: jhk1@khu.ac.kr

Key words: Lycii radicis cortex, glucocorticoids, glucocorticoidinduced osteoporosis, MC3T3-E1, Runx2 morphogenetic protein 2 in the MC3T3E-1 cell line. LRC also significantly reduced GC-induced osteoporosis and exerted anti-inflammatory effects in vivo. In addition, LRC inhibited the reduction of calbindin-D28k in the kidney. Overall, the results of the present study suggest that the use of LRC alleviates GC-induced secondary osteoporosis.

\section{Introduction}

Glucocorticoids (GCs), also known as steroids, are potent immunity regulators widely used in the treatment of inflammatory diseases. However, despite their effectiveness, GC usage is strictly controlled due to severe side-effects, such as osteoporosis, diabetes, impaired immune systems and Cushing's syndrome (1). Although numerous alternative drugs have been developed, the use of GCs has not decreased due to their effectiveness. GC long-term treatment has been reported as a cause of secondary osteoporosis (2). Diseases that may be the cause of secondary osteoporosis include malabsorption syndrome (3), hypogonadism (4) and Cushing's disease induced by the long-term use of GCs, unlike primary osteoporosis, which is caused by aging and menopause (5). Factors that cause secondary osteoporosis include drugs, such as anti-epileptic drugs (6) and antidepressants (7); among these, GCs are the most representative. The long-term use of GC results in rapid bone loss, and patients who undergo long-term GC treatment are at a higher a risk of bone fractures (8).

GC resistance is a condition that causes an increase in GC levels in the body and eventually causes side-effects (9). Therefore, controlling GC resistance is a crucial step to overcoming the side-effects. The GC receptor (GR) is known to bind GCs to regulate immune responses and to control cytokines through NF- $\kappa \mathrm{B}$ transcription $(9,10)$. GC resistance can reduce the affinity of the GR and may negatively affect its binding ability (9). However, the exact mechanisms involved remain unclear. Thus, further research on the mechanisms of $\mathrm{GC}$ resistance is required in order to understand its occurrence and prevent GC-induced osteoporosis (GIOP), as well as the side-effects caused by GC resistance.

Lycii radicis cortex (LRC) has been used to regulate high blood pressure, body temperature, pain and bone disorders in East Asia $(11,12)$. LRC has been shown to be involved in bone metabolism; LRC has been shown to inhibit osteoclast differentiation and to exert anti-osteoporotic effects in 
ovariectomized rats (13). LRC has also been shown to promote osteoblast differentiation (14). Kukoamine B, a component of LRC, has been shown to exert anti-osteoporotic effects through the control of osteoblasts and osteoclasts (15). However, its association with the effects of GC-induced osteoporosis has not yet been studied. In addition, the regulatory effects of LRC on GC-GR resistance have not yet been demonstrated, at least to the best of our knowledge.

The results demonstrated in the present study confirmed that osteoporosis was not induced in the GOIP model without allergic contact dermatitis (ACD) treatment. These results differ from those of previously published studies demonstrating that osteoporosis occurred in the group treated with only GC $(16,17)$. Therefore, the present study evaluated the effects of LRC in animal models with underlying disease. To the best of our knowledge, research methods to elucidate the mechanisms responsible for the side-effects of GCs have not been developed sufficiently to date. Therefore, the present study aimed to establish the research methodology for the evaluation of the effects of Korean drugs on bone loss induced by GCs used for ACD. The present study investigated the regulatory effects of $\mathrm{LRC}$ on the expression of GR in mouse macrophages, and in GC-induced bone loss in vivo and in vitro. The results suggest the potential for a new animal model of GIOP, and demonstrate the potential use of LRC as an alternative treatment for secondary osteoporosis.

\section{Materials and methods}

Reagents and antibodies. Dexamethasone (DEX; $\mathrm{C}_{22} \mathrm{H}_{29} \mathrm{FO}_{5}$; molecular weight, $392.46 \mathrm{~g} / \mathrm{mol}$; cat. no. D4902), a representative GC, lipopolysaccharide (LPS), scopoletin and 2,4-dinitrochlorobenzene (DNCB) were obtained from Sigma-Aldrich (Merck KGaA). Institute of Cancer Research (ICR) mice were supplied by the Animal Center of NARA Biotech. Phosphorylated (p)-NF- $\kappa$ B (cat. no. 3033) and p-GR antibodies (cat. no. 4161S) were purchased from Cell Signaling Technology, Inc. Bone morphogenetic protein 2 (BMP-2, cat. no. ab14933) and Runt-related transcription factor 2 (Runx2, cat. no. ab76956) antibodies were purchased from Abcam. Actin (cat. no. sc-8432) and Lamin B antibody (cat. no. sc-374015) was obtained from Santa Cruz Biotechnology, Inc., calbindin-D28k antibody (cat. no. PA1-931) was obtained from Thermo Fisher Scientific, Inc., and HRP-conjugated IgG antibody (cat. no. 115-035-062) was obtained from Jackson ImmunoResearch Laboratories, Inc. FBS, penicillin/streptomycin and PBS were provided by Invitrogen; Thermo Fisher Scientific, Inc. CellTiter $96^{\circledR}$ AQueous Non-Radioactive Cell Proliferation assay was obtained from Promega Corporation. Reverse transcription PCR (RT-PCR) primers were purchased from GenoTech Corp.

Preparation of LRC. LRC was obtained from Kyung Hee University Medical Center. LRC was boiled for $2 \mathrm{~h}$ with water at a 1:1 ratio. The filtered extract was freeze-dried using a lyophilizer. The yield was $6 \%$ (dried powder, $30 \mathrm{~g}$ ). A voucher specimen (KH076) was deposited at the Herbarium of the Department of Anatomy at Kyung Hee University. The dried extract was dissolved in distilled deionized water, filtered through a $0.22-\mu \mathrm{m}$ syringe filter system (RephiLe Bioscience) and stored at $-20^{\circ} \mathrm{C}$ until use.
Establishment of the animal model. All animal experiments were approved by the Kyung Hee University Animal Care and Use Committee [approval no. KHUASP(SE)-17-082]. A total of 32 male ICR mice (10 weeks old; weighing $35 \mathrm{~g}$ ) were bred in a controlled room $\left(22 \pm 2^{\circ} \mathrm{C}\right.$ temperature, $50 \pm 10 \%$ humidity, 12-h light/dark cycle).

The experimental conditions were as follows: i) Mice in the normal condition treated with PBS and olive oil (9:1) only (Fig. 1A, n=8); ii) the ACD + topically applied (TA) GC condition, where DEX was TA following the induction of ACD (Fig. 1B, n=8); iii) the ACD + subcutaneously (SC) injected GC condition, where DEX was SC injected following the induction of ACD (Fig. 1C, n=8); and iv) the GC (SC) condition, where DEX was SC injected without the induction of ACD (Fig. 1D, n=8).

For the induction of ACD, the backs of the mice were challenged with $200 \mu \mathrm{l} 1 \%$ DNCB for 3 days. After 4 days, $0.5 \% \mathrm{DNCB}$ was applied to the backs of the mice 3 days per week for 8 weeks to induce ACD. The GC (SC) group was not challenged with DNCB. In the ACD + GC (TA) group, $2 \mathrm{mg} / \mathrm{kg}$ DEX in $200 \mu \mathrm{l}$ PBS/olive oil (9:1) were applied to the dorsal skin of the mice 3 days per week for the induction of GC-related side-effects. In the ACD + GC (SC) and GC (SC) groups, $2 \mathrm{mg} / \mathrm{kg}$ DEX in $1 \%$ ethanol in saline were injected 3 days per week. The following conditions/observations were considered humane end points: i) Difficultly in ingesting food or water due to discomfort in walking; ii) the mouse became unconscious or did not react to external stimuli; iii) a weight loss $\geq 20 \%$ compared with other mice of the same age; iv) severe infection, laceration and bleeding at the stimulation site; and v) difficulty in maintaining a normal posture due to weak energy. During the process of the animal experiment, no mice died or exhibited signs which would lead to humanitarian termination. At the end of the animal experiments, the mice were sacrificed by cervical dislocation after collecting $2 \mathrm{ml}$ blood under deep anesthesia with $5 \%$ isoflurane diluted in $\mathrm{O}_{2}$. The femur and dorsal skin tissues were collected, and the muscles around the femur were neatly removed.

Design of experiments to evaluate the effects of LRC on GIOP models. Following the establishment of the GIOP animal model, to determine the effect of LRC on bone loss inhibition in GIOP, a model of TA-induced osteoporosis under the ACD condition was used in 32 new ICR mice (10 weeks old; weighing $35 \mathrm{~g}$, for 56 days). The LRC low dose was considered to be $50 \mathrm{mg} / \mathrm{ml}$, and the high dose was considered to be $100 \mathrm{mg} / \mathrm{ml}$. The mice were then divided into 4 groups (n=8/group) as follows: The normal group without DNCB and DEX stimulation and PBS/olive oil (9:1)-treated group (Nor), DNCB-sensitized and DEX-treated group (DEX), LRC $50 \mathrm{mg} / \mathrm{kg}$-treated group (LRC_Low) and the LRC 100 mg/kg-treated group (LRC_High) (Fig. 2).

Histological analysis and immunohistochemistry (IHC). The skin and femur tissues of the mice were embedded in $10 \%$ neutral buffered formalin for $24 \mathrm{~h}$. Micro-computed tomography (CT) analysis was conducted according to Kim et al (18). Briefly, the left femurs were analyzed using a cone beam micro-CT system (SkyScan1176; Skyscan; Kontich). The femurs were scanned from the knee for 500 frames, and the images were visualized 


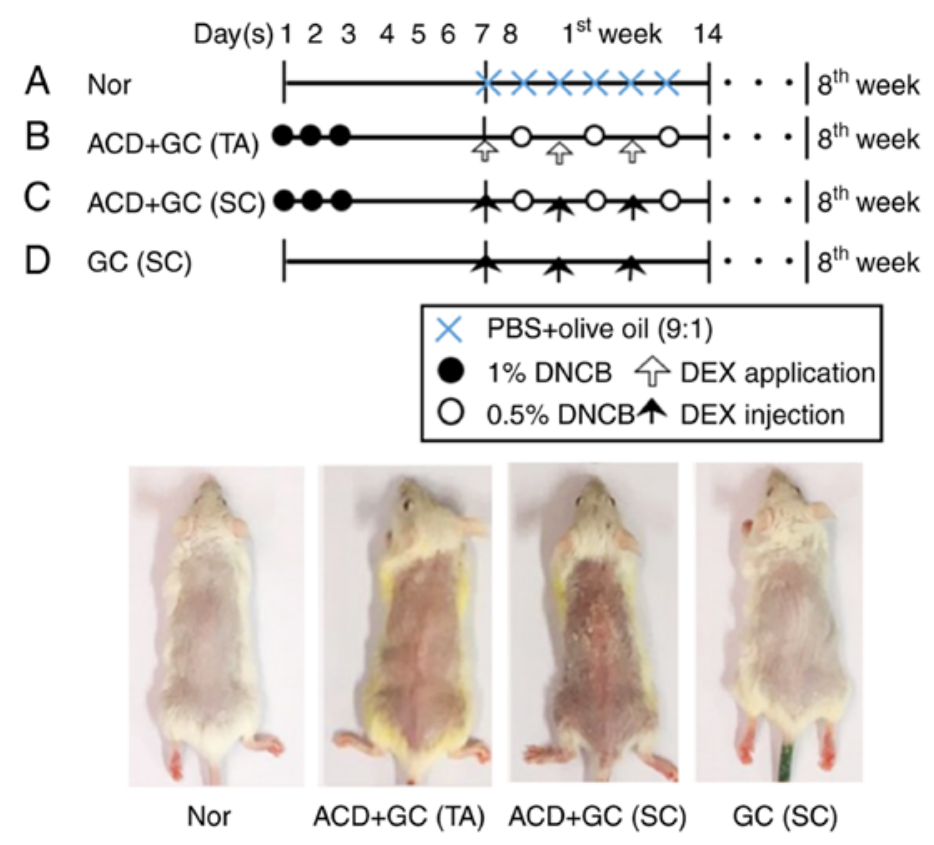

Figure 1. Establishment of an experimental animal model of GIOP. (A) Mice in the normal condition treated with PBS and olive oil (9:1) only. (B) ACD + GC (TA) group, where DEX was topically treated following the induction of ACD. (C) ACD + GC (SC) group, where DEX was injected for treatment under the skin following the induction of ACD. (D) GC (SC) group, where DEX was injected without the induction of ACD. DEX was subdivided into the subcutaneous injection GC (SC) groups without causing underlying diseases. ACD, allergic contact dermatitis; GC, glucocorticoid; GIOP, GC-induced osteoporosis; TA, topically applied; SC, subcutaneously injected; DEX, dexamethasone; DNCB, 2,4-dinitrochlorobenzene.

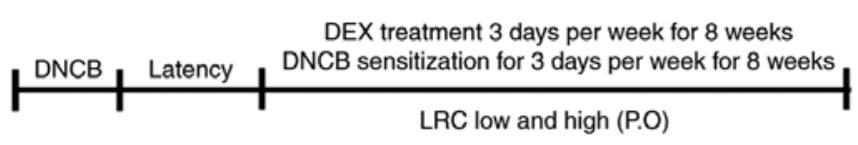

Figure 2. Design of experiments to evaluate the effects of LRC on GC-induced osteoporosis models. All topical treatments were applied to the back of each animal as a $200 \mu 1$ solution. The normal group received a vehicle mixed with PBS and olive oil. DEX and LRC groups were first sensitized to $1 \%$ DNCB for 3 days. After latency, $0.5 \%$ DNCB was sensitized 3 times per week. DEX was then administered as a treatment at a concentration of $2 \mathrm{mg} / \mathrm{ml} 3$ times per week. LRC mice received oral LRC daily at doses of 50 and $100 \mathrm{mg} / \mathrm{ml}$ in distilled water. LRC, Lycii radicis cortex; DNCB, 2,4-dinitrochlorobenzene; GC, glucocorticoid; DEX, dexamethasone.

using Data Viewer software (v.1.5.1.9; Skyscan; Kontich). Structural parameters were determined using CT analyzer software (v1.15.4.0; Skyscan; Kontich). Bone morphometric parameters, such as bone mineral density (BMD, $\left.\mathrm{g} / \mathrm{cm}^{3}\right)$, bone volume/total volume (BV/TV, \%), trabecular thickness (Tb.Th, $\mathrm{mm}$ ), trabecular separation ( $\mathrm{Tb} . \mathrm{Sp}, \mathrm{mm}$ ), trabecular number (Tb.N, 1/mm) and bone surface density (BS/TV, 1/U) were measured.

Tissue staining was performed according to a previous study (19). In brief, paraffin-embedded tissue sections were prepared for IHC by incubation with $0.3 \% \mathrm{H}_{2} \mathrm{O}_{2}$ in methanol for $30 \mathrm{~min}$. The tissues were then placed in proteinase $\mathrm{K}$ buffer (Sigma-Aldrich; Merck KGaA) for 20 min. Tissues were incubated at room temperature for $1 \mathrm{~h}$ in blocking solution (10\% normal serum, Gibco; Thermo Fisher Scientific, Inc.). The tissues were treated anti-calbindin-D28k antibody (1:100) overnight at $4^{\circ} \mathrm{C}$, and then incubated at the room temperature for $1 \mathrm{~h}$ with peroxidase-labelled IgG (1:100; rabbit; cat. no. BA-1000, Vector Laboratories, Inc.) for $1 \mathrm{~h}$. Tissue sections were then stained using the Vector ABC kit (Vector
Laboratories, Inc.) as recommended by the manufacturer, and then incubated at room temperature for $7 \mathrm{~min}$ with diaminobenzidine (DAB) tetrachloride mixed with $\mathrm{NiCl}_{2}+\mathrm{H}_{2} \mathrm{O}$ (Vector Laboratories, Inc.). Finally, the tissues were counterstained using hematoxylin. The femur tissues were decalcified in EDTA-2Na for 3 weeks and then embedded in paraffin. The femur tissue was fixed using $10 \%$ neutral buffered formalin and the tissues were embedded with paraffin. The embedded tissues were cut into $5-\mu \mathrm{m}$-thick sections and stained with hematoxylin and eosin (H\&E, Sigma-Aldrich, Merck KGaA) at room temperature for 10 and $10 \mathrm{~min}$, respectively. The number of mast cells was counted following toluidine blue staining (Sigma-Aldrich, Merck KGaA) at room temperature for $2 \mathrm{~min}$. All sections were examined under a light microscope (DP73; Olympus Corporation).

ELISA. Serum was obtained by centrifuging the collected blood at $14,310 \mathrm{x}$ g for $20 \mathrm{~min}$ at $4^{\circ} \mathrm{C}$. Measurement of the expression of bone-related markers, such as receptor activation of NF-KB ligand (RANKL), osteoprotegerin (OPG), sclerostin (SOST), Dickkopf-1 (DKK1) and bone-derived fibroblast growth factor 23 (FGF23) in serum was performed by NEW Korea Industrial Co., Ltd. and was detected using Multiplex ELISA.

Cell cytotoxicity assay. Murine RAW 264.7 cells (Korean Cell Line Bank; Korean Cell Line Research Foundation) were cultured in DMEM (Welgene, Inc.) containing 10\% FBS and $1 \%$ penicillin/streptomycin. Osteoblastic MC3T3-E1 cells were cultured in $\alpha$-MEM containing $10 \%$ FBS and $1 \%$ penicillin/streptomycin (Gibco; Thermo Fisher Scientific, Inc.). The cell cultures were maintained at $37^{\circ} \mathrm{C}$ in a humidified atmosphere of $5 \% \mathrm{CO}_{2}$ in air. The cells were seeded in a 
Table I. List of primers used for RT-PCR.

\begin{tabular}{|c|c|c|c|c|}
\hline Marker name & Gene name & Accession no. & Species & Sequence \\
\hline RUNX2 & Runx2 & NM_009820.5 & Mouse & $\begin{array}{l}\text { F: CCAACCGAGTCATTTAAGGCT } \\
\text { R: GCTCACGTCGCTCATCTTG }\end{array}$ \\
\hline Osteocalcin (OCN) & Bglap2 & NM_001032298.3 & Mouse & $\begin{array}{l}\text { F: GCA ATA AGG TAG TGA ACA GAC TCC } \\
\text { R: GTT TGT AGG CGG TCT TCA AGC }\end{array}$ \\
\hline ALP & Alpl & NM_001287172.1 & Mouse & $\begin{array}{l}\text { F: CGGGACTGGTACTCGGATAA } \\
\text { R: TGAGATCCAGGCCATCTAGC }\end{array}$ \\
\hline Osteonectin (OSN) & Sparc & NM_001290817.1 & Mouse & $\begin{array}{l}\text { F: AAACATGGCAAGGTGTGTGA } \\
\text { R: TGCATGGTCCGATGTAGTC }\end{array}$ \\
\hline Osteopontin (OPN) & Spp1 & NM_001290377.1 & Mouse & $\begin{array}{l}\text { F: TCTGATGAGACCGTCACTGC } \\
\text { R: AGGTCCTCATCTGTGGCATC }\end{array}$ \\
\hline Procol (COL1) & Colla1 & NM_007742.4 & Mouse & $\begin{array}{l}\text { F: GCTCCTCTTAGGGGCCACT } \\
\text { R: CCACGTCTCACCATTGGGG }\end{array}$ \\
\hline GAPDH & Gapdh & NM_008084.3 & Mouse & $\begin{array}{l}\text { F: ACTTTGTCAAGCTCATTTCC } \\
\text { R: TGCAGCGAACTTTATTGATG }\end{array}$ \\
\hline Caspase-6 & Casp6 & NM_009811.4 & Mouse & $\begin{array}{l}\text { F: AGACAAGCTGGACAACGTGACC } \\
\text { R: CCAGGAGCCATTCACAGTTTCT }\end{array}$ \\
\hline Caspase-9 & Casp9 & NM_001277932.1 & Mouse & $\begin{array}{l}\text { F: GGATCCATGCCCAGACCAGTGGACATTGG } \\
\text { R: GGTCTAGATTATGATGTTTTAAAGAAAAG }\end{array}$ \\
\hline IAP-1 & Birc3 & NM_007464.3 & Mouse & $\begin{array}{l}\text { F: AAGTGTGTATGGACCGAGAG } \\
\text { R: GGACCATTAGTCTTGTTCAG }\end{array}$ \\
\hline IAP-2 & Birc2 & NM_001291503.1 & Mouse & $\begin{array}{l}\text { F: TGTGTATGGACAGAGAGGTT } \\
\text { R: CAGCTTCTGATGTCCAACAA }\end{array}$ \\
\hline X-IAP & Xiap & NM_001301641.1 & Mouse & $\begin{array}{l}\text { F: ATACGGAGGATGAGTCAAGT } \\
\text { R: GGTTGAACGTAATGACGGTG }\end{array}$ \\
\hline
\end{tabular}

RUNX2, runt-related transcription factor 2; ALP, alkaline phosphatase; OCN, osteocalcin; OPN, osteopontin; OSN, osteonectin; Colla1, collagen, type I, $\alpha 1$; RT-PCR, reverse transcription polymerase chain reaction; GAPDH, glyceraldehyde 3-phosphate dehydrogenase.

96-well plate. The cells were subjected to experimental methods according to a previous study (13). Cells were treated only with 10,50 and $100 \mu \mathrm{g} / \mathrm{ml} \mathrm{LRC} \mathrm{or} \mathrm{with} 1 \mu \mathrm{M} \mathrm{DEX}$ for $24 \mathrm{~h}$. An MTS solution was added at $20 \mu \mathrm{l}$ per well. After $2 \mathrm{~h}$, cell viability was measured at $490 \mathrm{~nm}$ using an ELISA reader (Molecular Devices, LLC). The optical density (OD) values of untreated cells were normalized to $100 \%$. MC3T3-E1 cells were seeded into 96-well plates and incubated in a humidified incubator at $37^{\circ} \mathrm{C}$ overnight. Following $48 \mathrm{~h}$ of culture, Cell Counting Kit-8 (CCK-8; Dojindo Molecular Technologies, Inc.) assay was performed according to the manufacturer's instructions. The medium in the 96-well plates was exchanged for $100 \mu 1$ $20 \% \mathrm{CCK}-8$ solution. After incubating the cells for $1 \mathrm{~h}$ at $37^{\circ} \mathrm{C}$, the absorbance at a wavelength of $450 \mathrm{~nm}$ was measured with a microplate reader (Versamax; Molecular Devices, LLC). The percentage of cell viability was calculated based on the control wells. Lactate dehydrogenase (LDH) release was measured using a LDH assay kit (Dojindo Molecular Technologies, Inc.) according to the manufacturer's instructions.

Semi-quantitative RT-PCR. RT-PCR was conducted to a previous study (20). MC3T3-E1 cells were seeded at a density of $1 \times 10^{6}$ cells/well in a 6 -well plate for $24 \mathrm{~h}$. The cells were then treated with 10,50 and $100 \mu \mathrm{g} / \mathrm{ml}$ LRC and co-treated with DEX $(1 \mu \mathrm{M})$ for either 2 or 4 days. The medium was changed every 2 days. Total RNA was extracted using TRIzol $^{\circledR}$ (Invitrogen; Thermo Fisher Scientific, Inc.). cDNA was prepared using SuperScript II reverse transcriptase (Invitrogen; Thermo Fisher Scientific, Inc.) and cDNA was then amplified in a PCR machine (C1000 Touch ${ }^{\mathrm{TM}}$ Thermal Cycler, Bio-Rad Laboratories, Inc.) using Taq polymerase and each primer. GAPDH was used as the reference gene. The list of primers used is presented in Table I. These PCR reactants was separated in an $2 \%$ agarose gel and visualized using $\mathrm{N} \alpha \mathrm{BI}$ (Neoscience). mRNA expression was measured using ImageJ software (v1.52a; National Institutes of Health).

Alizarin Red S staining. Alizarin red S staining was used in the mineralization assay of MC3T3-E1. Osteoblast differentiation and Alizarin Red S staining were conducted as described in the study by Kim et al (20). Briefly, MC3T3-E1 cells were incubated in osteogenic differentiation medium ( $\alpha$-MEM containing $10 \mathrm{mM} \beta$-glycerophosphate and $25 \mu \mathrm{g} / \mathrm{ml}$ ascorbic acid) at a density of $5 \times 10^{5}$ cells/well in a 24 -well plate for $24 \mathrm{~h}$. MC3T3-E1 cells were treated with 10,50 and $100 \mu \mathrm{g} / \mathrm{ml}$ LRC and co-treated with DEX $(1 \mu \mathrm{M})$ for 4 weeks. The cells were fixed with $80 \%$ ice-cold ethanol for $1 \mathrm{~h}$ and stained with $1 \mathrm{w} / \mathrm{v}(\%)$ Alizarin Red S solution (Daejung Chemicals \& Metals Co., Ltd.) at the room temperature for $5 \mathrm{~min}$. The wells were destained with $500 \mu 110 \%$ cetylpyridinium chloride for 
15 min. The OD value of the Alizarin Red S-stained cells was measured at $570 \mathrm{~nm}$ using a spectrophotometer (Versamax; Molecular Devices, LLC).

Western blot analysis. To confirm the effect of LRC on osteogenesis-related markers, MC3T3-E1 cells were seeded at a density of $1 \times 10^{6}$ cells/well in a 6 -well plate in a humidified incubator at $37^{\circ} \mathrm{C}$ for $24 \mathrm{~h}$. MC3T3-E1 cells were treated with 10,50 and $100 \mu \mathrm{g} / \mathrm{ml} \mathrm{LRC}$ and co-treated with $\operatorname{DEX}(1 \mu \mathrm{M})$ for 2 days. Whole protein lysate was extracted using RIPA buffer (50 mM Tris-Cl, $150 \mathrm{mM} \mathrm{NaCl}, 1 \% \mathrm{NP}-40,0.5 \%$ sodium deoxycholate and $0.1 \%$ SDS with protease inhibitor and phosphatase inhibitor 2 and 3 cocktails). To confirm the inhibitory effect of LRC on GC-induced resistance, RAW 264.7 cells were seeded at a density of $1 \times 10^{6}$ cells/well in a 6-well plate in a humidified incubator at $37^{\circ} \mathrm{C}$ for 2 days. Subsequently, RAW 264.7 cells were cultured with 10 and $100 \mu \mathrm{g} / \mathrm{ml}$ LRC or 0.1 and $1 \mu \mathrm{M}$ $\mathrm{DEX}+1 \mu \mathrm{g} / \mathrm{ml}$ LPS for 2 or $24 \mathrm{~h}$. The cells from each well were lysed to extract nuclear proteins, which were purified using a NE-PER Nuclear and Cytoplasmic Extraction reagent kit (Pierce; Thermo Fisher Scientific,Inc.) according to the manufacturer's instructions. The extracted protein was quantified through bicinchoninic acid assay. Western blot analysis was conducted according to a previous study (13). Briefly summarized, the same amount of protein $(30 \mu \mathrm{g})$ was separated by protein size through electrophoresis on $10 \%$ SDS-gel $(100 \mathrm{~V}, 1.5 \mathrm{~h})$, and then transferred to nitrocellulose membranes (Whatman plc; Cytiva). To prevent non-specific protein binding, the membrane was reacted with $5 \%$ skim milk in $0.05 \%$ TBST at the room temperature for $1 \mathrm{~h}$, and each primary antibody was attached at $4^{\circ} \mathrm{C}$ overnight. The dilution concentration of each antibody was as follows: BMP-2, 1:500; Runx2, 1:1,000; actin, 1:500; p65, 1:1,000; p-GR (ser211), 1:500; p-GR (ser226) and Lamin B, 1:500. The secondary antibodies (1:10,000; source: Rabbit; cat. no. 111-035-045; 1:10,000; source: Mouse; cat. no. 115-035-062; Jackson ImmunoResearch Laboratories, Inc.) were then reacted at room temperature for $1 \mathrm{~h}$ and visualized using enhanced chemiluminescence (Santa Cruz Biotechnology, Inc.). Protein expression was measured using ImageJ software (v1.52a; National Institutes of Health). The expression of each target band was quantified using Actin and Lamin B.

Gas chromatography (GC)/mass spectrometry (MS) analysis of $L R C$. The phytochemical analysis of LRC was performed with an Agilent 6890 GC apparatus interfaced to an Agilent 5973 MS system equipped with an electron ionization (EI) source and autoinjector (Agilent Technologies, Inc.). GC/MS was conducted according to a previous study (21). The GC system was built with a DB-5 column $(30.0 \mathrm{~m} \mathrm{x}$ $0.25 \mathrm{~mm} \times 0.25 \mu \mathrm{m})$. The temperature varied from $80^{\circ} \mathrm{C}$ $(5 \mathrm{~min})$ to $200^{\circ} \mathrm{C}$ at $5^{\circ} \mathrm{C} / \mathrm{min}$, and the injection volume was $2 \mu \mathrm{l}$. Injection was performed in the split mode adjusted to 1:5. The carrier gas was helium at $1.0 \mathrm{ml} / \mathrm{min}$. The inlet, source and quadrupole temperatures were set at 290,230 and $190^{\circ} \mathrm{C}$, respectively. For MS detection, the EI mode with an ionization energy of $70 \mathrm{eV}$ was used, with a mass range at m/z 50-800. Agilent ChemStation software (Agilent Technologies, Inc.) was used for data processing. The phytochemical compounds were identified by mass fragmentation patterns compared via Wiley Spectral Library search.
Statistical analysis. The data are presented as the mean \pm SEM. All experiments were repeated at least 3 times. All data were analyzed using GraphPad Prism software (v5.01; GraphPad Software, Inc.). One-way ANOVA was used to evaluate the treatment effect, a single group was post-tested using Dunnett's, and multiple comparisons between different groups were post-tested using Tukey's. $\mathrm{P}<0.05$ was considered to indicate a statistically significant difference.

\section{Results}

Evaluation of the established GIOP models. The present study aimed to model osteoporosis induction following the systemic injection or skin application of GC following the development of a specific inflammatory disease, namely ACD. Through the analysis of bone density through micro-CT and histological examination, GIOP found to be induced by the DEX dorsal skin application following the induction of ACD (Fig. 3A-C). In addition, as a result of bone microstructure analysis, BMD was significantly decreased in both the ACD + GC (TA) and ACD + GC (SC) groups, and the ACD + GC (TA) group exhibited significant differences in Tb.Sp, Tb.Th and BV/TV compared with those of the Nor group. However, the $\mathrm{ACD}+\mathrm{GC}(\mathrm{SC})$ group did not exhibit a significant difference in Tb.Sp or BV/TV (Fig. 3D-G).

Expression of calbindin-D28k in the duodenum and kidney of the animals in the experimental model. To evaluate the calcium absorption abilities of digestive organs, the expression of a calcium binding protein (calbindin-D28k) in the duodenum and kidney was evaluated (Fig. 4A and C). The expression of calbindin-D28k was significantly decreased in the ACD + GC (TA) group in both the duodenum and kidney. The expression of calbindin-D28k was also inhibited in the duodenum in the ACD + GC (SC) group. However, the expression of calbindin-D28k in the kidney of the ACD + GC (SC) group appeared to be decreased compared to that of the normal group; however, the difference was not statistically significant (Fig. 4B and D). On the whole, the results presented in Figs. 3 and 4 demonstrated that the induction of ACD was a prerequisite for the occurrence of GIOP. However, GIOP did not occur in animals without ACD. In addition, it was demonstrated that the TA group exhibited osteoporosis more markedly than the SC group, as reflected by bone microstructure or the expression of calbindin-D28k in the duodenum. Finally, an animal model was established by the TA of DEX under ACD inducing conditions.

Effect of LRC on bone loss in GIOP mouse femur. The present study attempted to compare the effects of LRC using the DEX administration method, which was applied to the $\mathrm{ACD}+\mathrm{GC}$ (TA) group. In both the micro-CT and histological examination experiments, LRC exerted an inhibitory effect on GC-induced osteoporosis (Fig. 5A and B). The results of bone microstructure analysis revealed that the LRC high group exhibited a significantly increased (BV/TV, Tb.N and BS/TV) or decreased (Tb.Sp) compared with the GC group (Fig. 5C-G). Tb.Th exhibited a tendency to increase in the LRC low and LRC high groups compared with the GC group, although the difference was not statistically significant (Fig. 5H). 


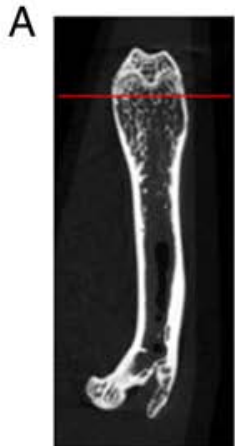

Nor

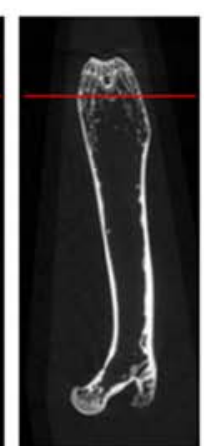

TA

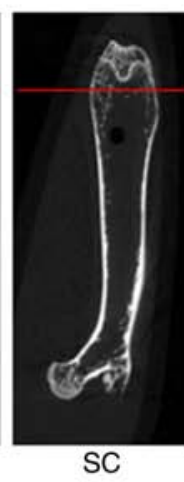

ACD

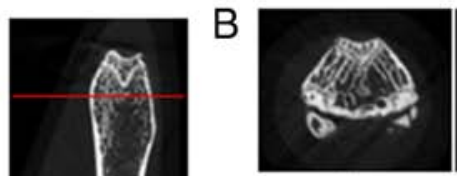

Nor

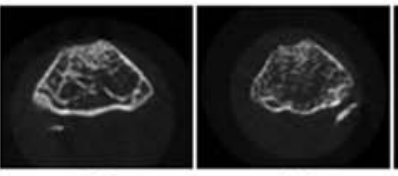

SC

ACD

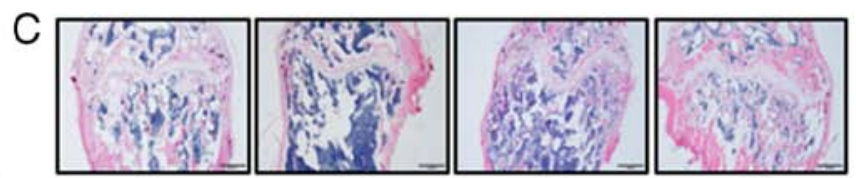

Nor

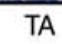

$\mathrm{SC}$

ACD

F

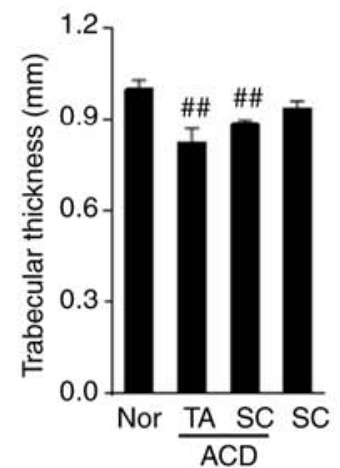

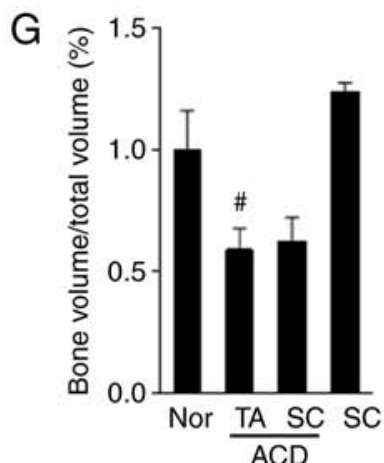

Figure 3. Bone structure analysis of mice femur via micro-computed tomography. (A) Horizontal cross-section of a mouse femur. (B) Vertical cross-section corresponding to the red line shown in (A). (C) Paraffin-embedded section of the mouse tissues stained with hematoxylin and eosin. (D) Bone mineral density, (E) trabecular separation, (F) trabecular thickness and (G) bone volume/total volume results for the different experimental condition. In the ACD + GC (TA) model, GIO was induced by applying DEX to the back of the animals following the induction of ACD with DNCB. In the ACD + GC (SC) group, DNCB induced ACD and then DEX was subcutaneously injected to induce GIOP. In the GC (SC) group, DEX was injected subcutaneously without causing ACD. ${ }^{\#} \mathrm{P}<0.05,{ }^{\# \#} \mathrm{P}<0.01$ vs. normal animals. Nor, normal group; ACD, allergic contact dermatitis; GC, glucocorticoid; GIOP, GC-induced osteoporosis; TA, topically applied; SC, subcutaneously injected; DEX, dexamethasone; DNCB, 2,4-dinitrochlorobenzene.

\section{A Duodenum}

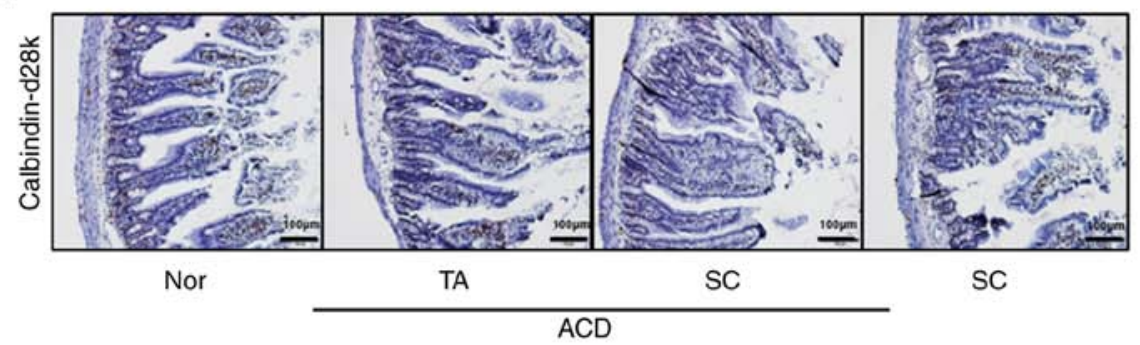

C Kidney

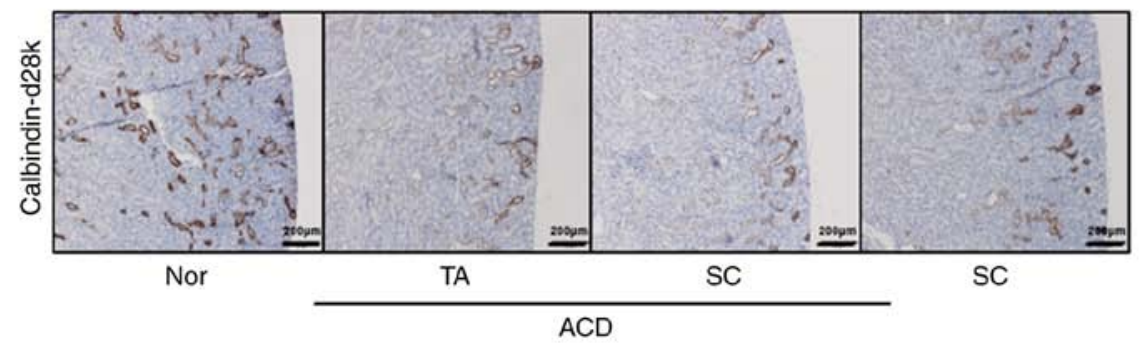

$\mathrm{B}$
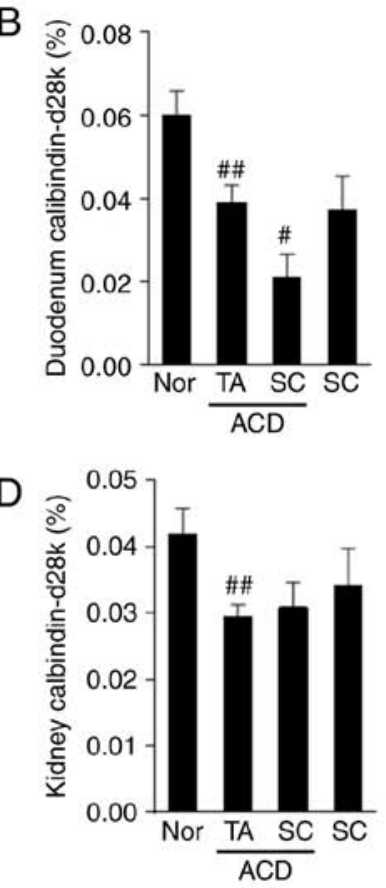

Figure 4. Comparison of the expression level of calbindin-D28k in the duodenum and kidney. (A) Duodenum tissues were evaluated using calbindin-D28k immunohistochemical staining. (B) The Calbindin-D28k stained areas in the duodenum were calculated using ImageJ software version 1.51j8. (C) Kidney tissues were evaluated using calbindin-D28k immunohistochemical staining. (D) The Calbindin-D28k stained areas in kidney were calculated using ImageJ software version $1.51 \mathrm{j} 8$. The brown areas stained with diaminobenzidine were selected to measure the density as a percentage of the total area. Data represent the mean \pm SEM. ${ }^{\#} \mathrm{P}<0.05,{ }^{\# \#} \mathrm{P}<0.01$ vs. the normal group. Nor, normal group; ACD, allergic contact dermatitis; GC, glucocorticoid; TA, topically applied; SC, subcutaneously injected. 
A

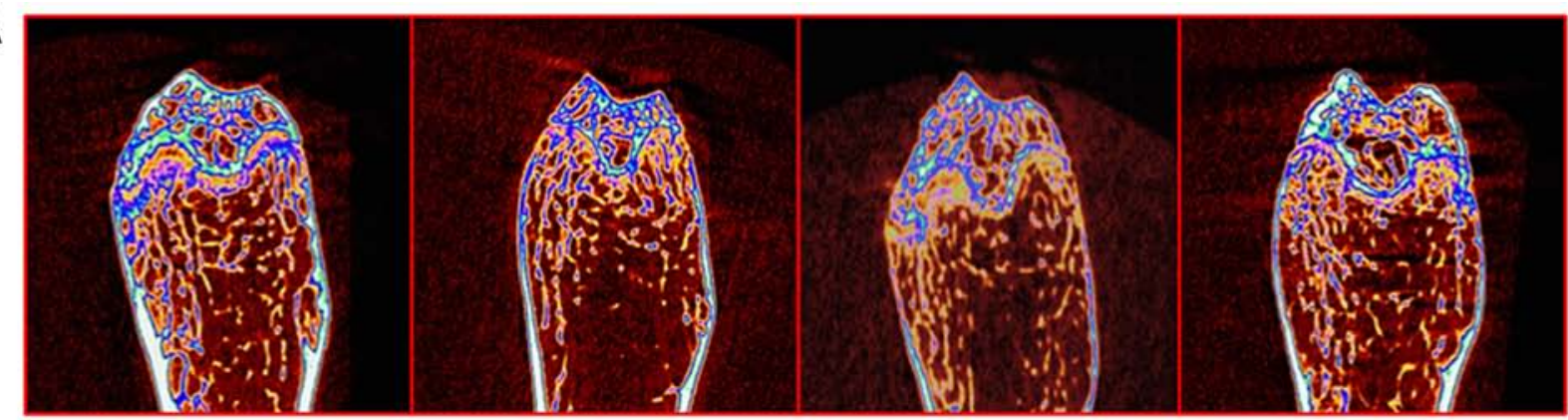

Nor

GC

LRC low

LRC high

B

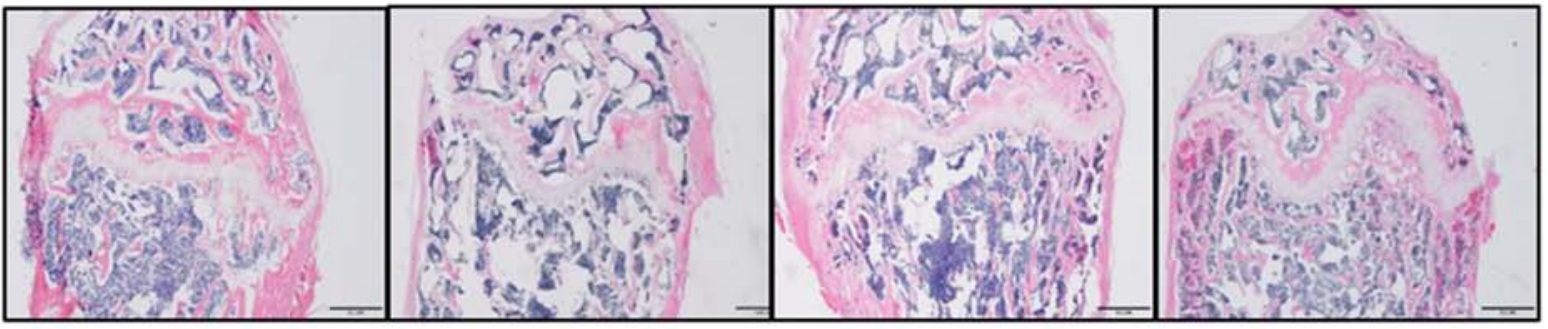

Nor

GC

LRC low

LRC high

C

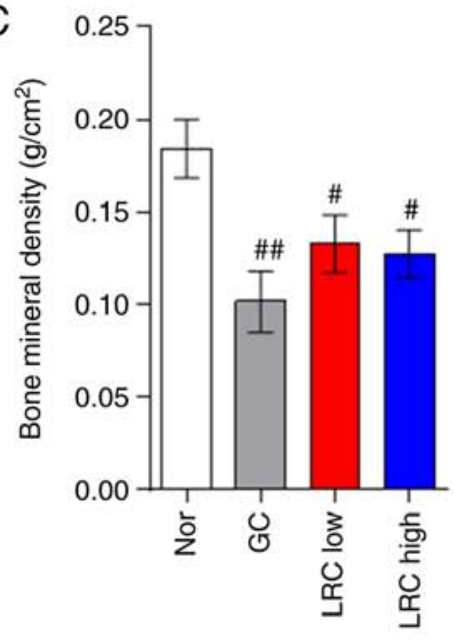

F

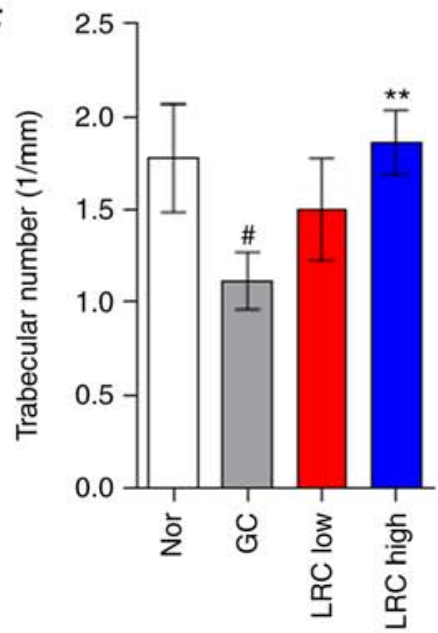

D

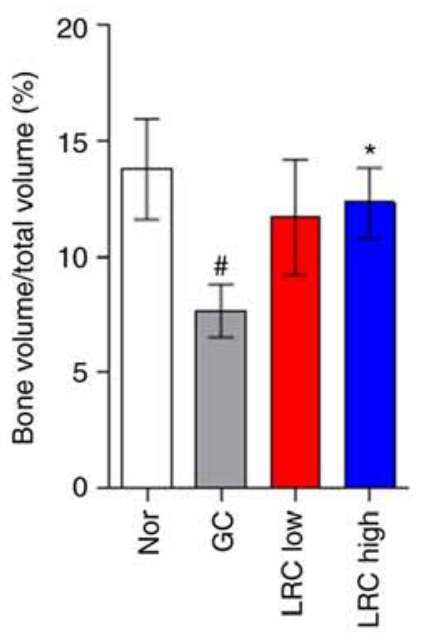

G

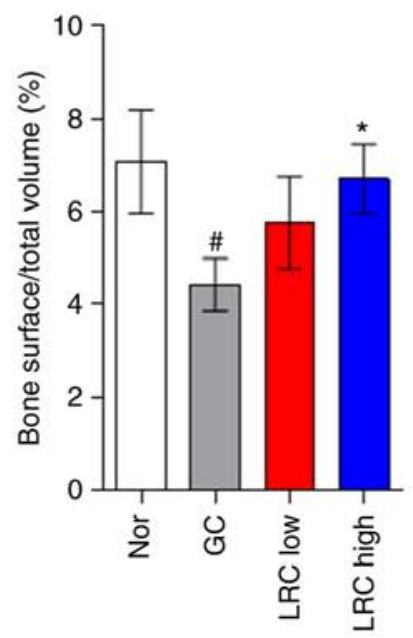

E

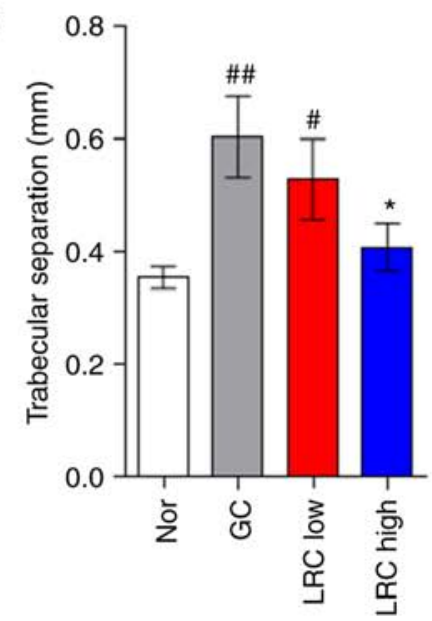

$\mathrm{H}$

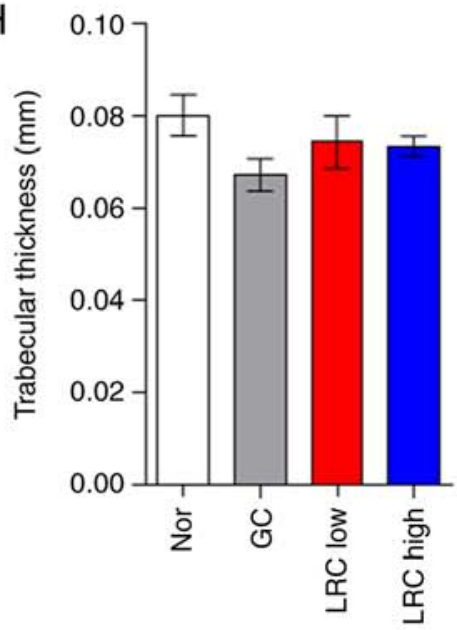

Figure 5. Effect of LRC on GIOP in an ACD mouse model. DEX $(2 \mathrm{mg} / \mathrm{kg})$ was applied for 8 weeks following the induction of ACD using 2,4-dinitrochlorobenzene on the skins of mice. LRC extract $(50$ and $100 \mathrm{mg} / \mathrm{kg}$ ) or distilled water were orally administered to the mice. (A) After 8 weeks, the mouse femurs were analyzed by micro-CT. (B) The femurs were sectioned and stained with hematoxylin and eosin. The mouse bone parameters such as (C) BMD, (D) BV/TV, (E) Tb.Sp, (F) Tb.N, (G) BS/TV and (H) Tb.Th were analyzed by micro-CT. Data represent the means \pm SEM of experiments. ${ }^{~} \mathrm{P}<0.05$, ${ }^{\# \prime} \mathrm{P}<0.01$ vs. normal animals; ${ }^{*} \mathrm{P}<0.05,{ }^{* *} \mathrm{P}<0.01$ vs. GC animals. LRC, Lycii radicis cortex; ACD, allergic contact dermatitis; GIOP, GC-induced osteoporosis; DEX, dexamethasone; CT, computed tomography; GC, glucocorticoid; bone mineral density, BMD; bone volume/total volume, BV/TV; trabecular separation, Tb.Sp; trabecular number, Tb.N; trabecular thickness, Tb.Th; bone surface density. 
A Duodenum

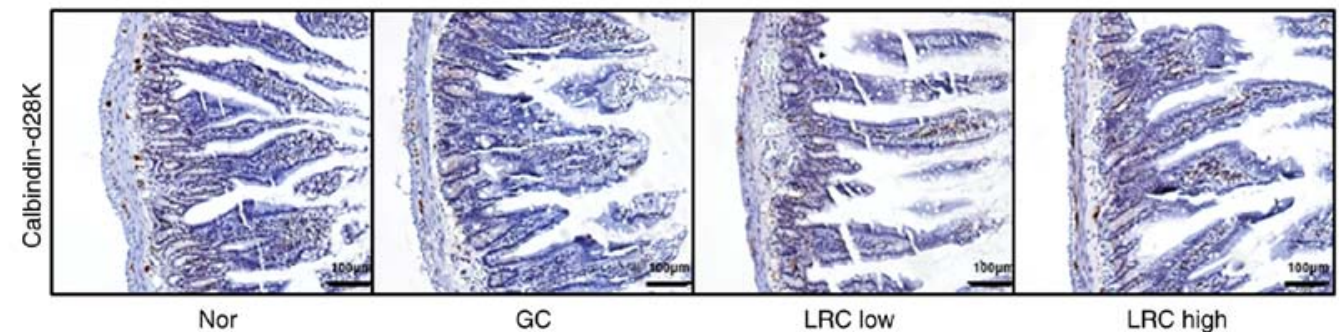

B
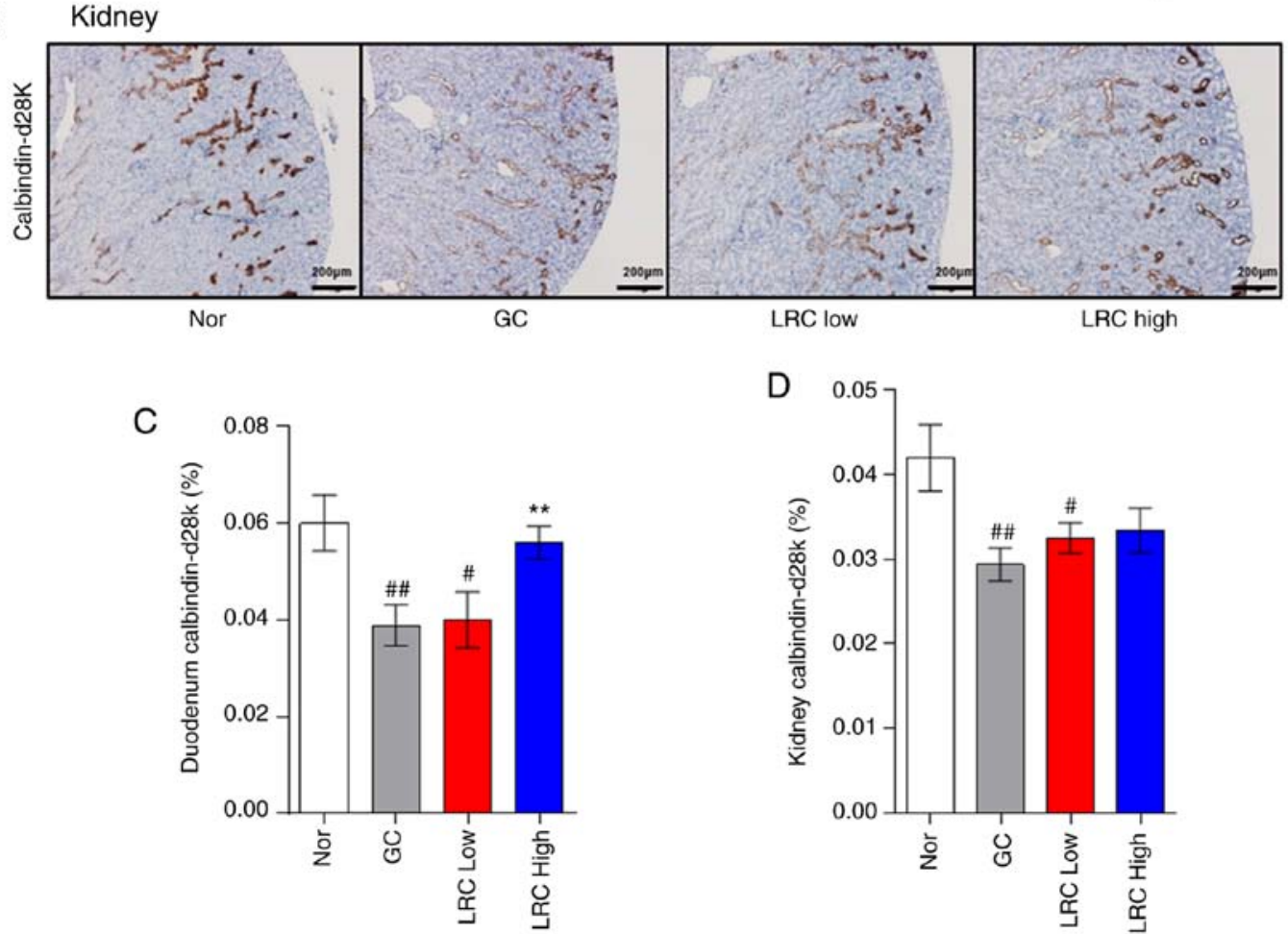

Figure 6. Effect of Lycii radicis cortex on calcium abortion in mice with glucocorticoid-induced osteoporosis. (A) Duodenum and (B) kidneys were evaluated using calbindin-D28k immunohistochemical staining. The level of calbindin-D28k in (C) duodenum and (D) kidney tissues was calculated using Image J. The brown areas stained with diaminobenzidine were extracted, and the threshold value was selected to measure only the density as a percentage of the total area. Data represent the mean \pm SEM. ${ }^{~} \mathrm{P}<0.05,{ }^{\# \#} \mathrm{P}<0.01$ vs. normal animals; ${ }^{* *} \mathrm{P}<0.01$ vs. GC animals. ACD, allergic contact dermatitis; GC, glucocorticoids; GIOP, GC induced osteoporosis; DEX, dexamethasone; IHC, immunohistochemistry.

Effect of LRC on calcium absorption in duodenum and kidney tissues. The LRC high group exhibited significantly increased duodenum calbindin-D28k levels (Fig. 6A and C). In the kidney tissue, calbindin-D28k expression was upregulated by LRC, although the difference was not significant (Fig. 6B and D).

Effect of LRC on DNCB-induced ACD. To investigate whether LRC maintains the anti-inflammatory effects of DEX $(22,23)$, the effects of LRC on immune cell infiltration number and skin thickness were evaluated in an animal model of ACD. The LRC high group exhibited a larger reduction in the number of mast cells in DNCB-induced ACD skin tissues compared with that of the GC group (Fig. 7A and D). The LRC low group and LRC high group did not exhibit a significant difference on the number of eosinophils compared with the GC group (Fig. 7B and E). The LRC high group experienced significantly increased epidermal thickness compared with that of the GC (DEX-treated) group. These results appear to be indicative of the protective effect of LRC against skin atrophy, which is one of the side-effects of GC (Fig. 7C and F). However, LRC did not significantly affect the thickness of the dermis (Fig. 7G).

Effect of LRC on osteoporosis-related mediators in serum, and on body and organ weight. The results of ELISA revealed that GC significantly increased the OPG and DKK1 levels, while the levels in the LRC-treated groups were not affected compared with the GC group (Table II). The GC group exhibited significantly decreased body, liver, thymus and spleen weight compared with the findings in the Nor group. LRC significantly increased the testis weight compared with that of the GC group. LRC increased liver weight compared with that of the GC group, although not significantly (Table III).

Effect of LRC on GC-induced osteoblastic MC3T3-E1 cell apoptosis. After confirming the ameliorating effects of LRC on GIOP in in vivo experiments, in order to analyze the mechanisms involved, the effects of LRC on the DEX-induced apoptosis and differentiation of osteoblasts were verified in 

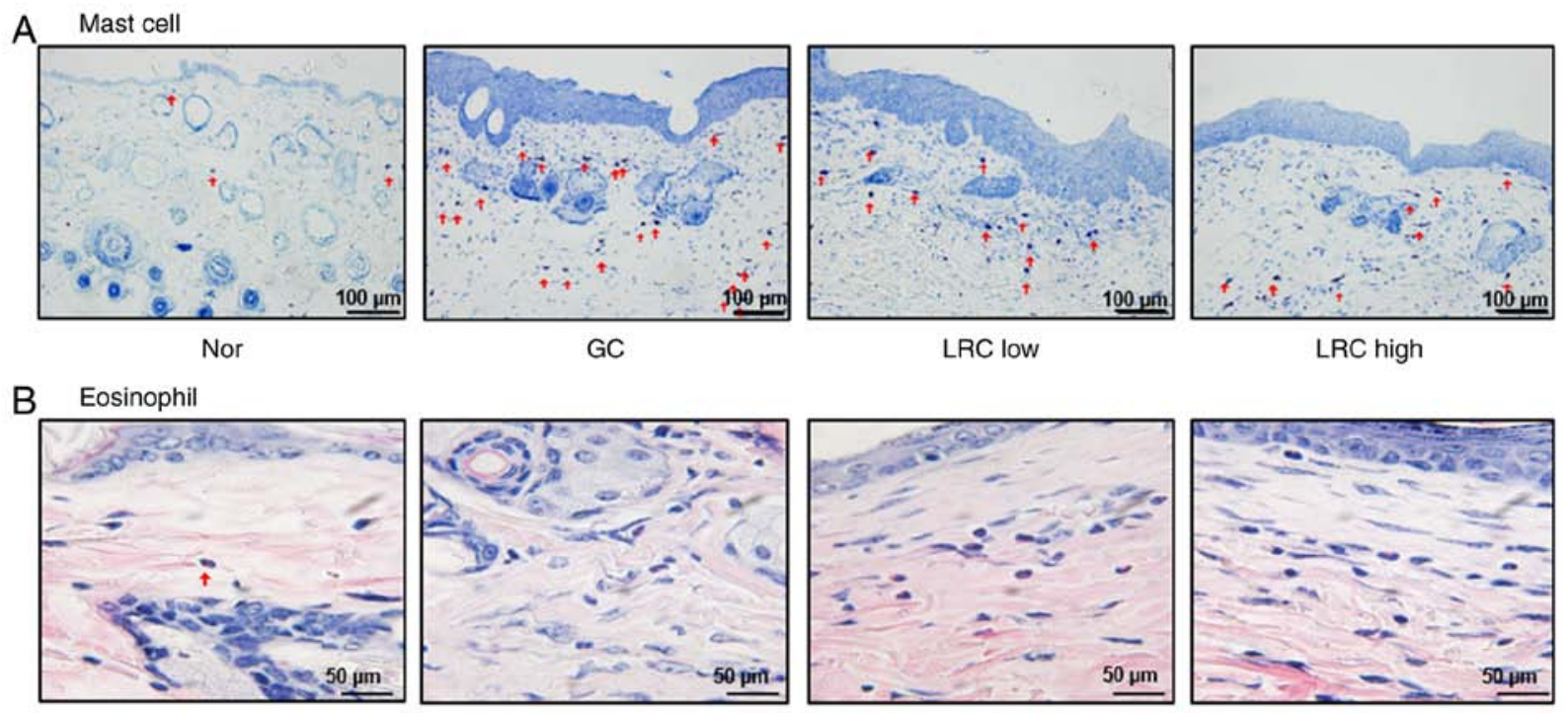

Nor

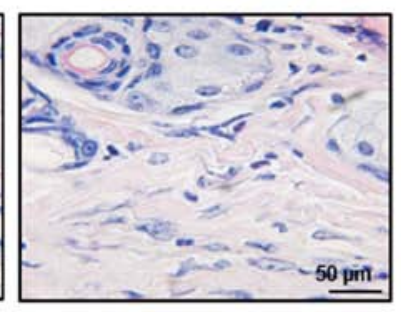

GC

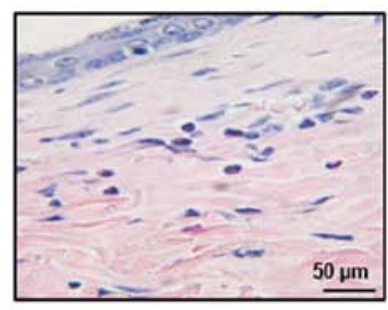

LRC low

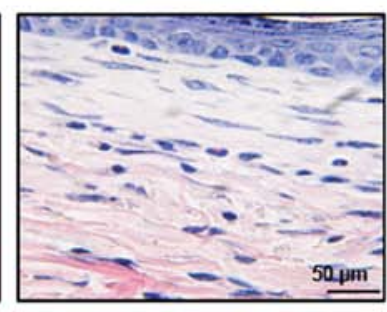

LRC high
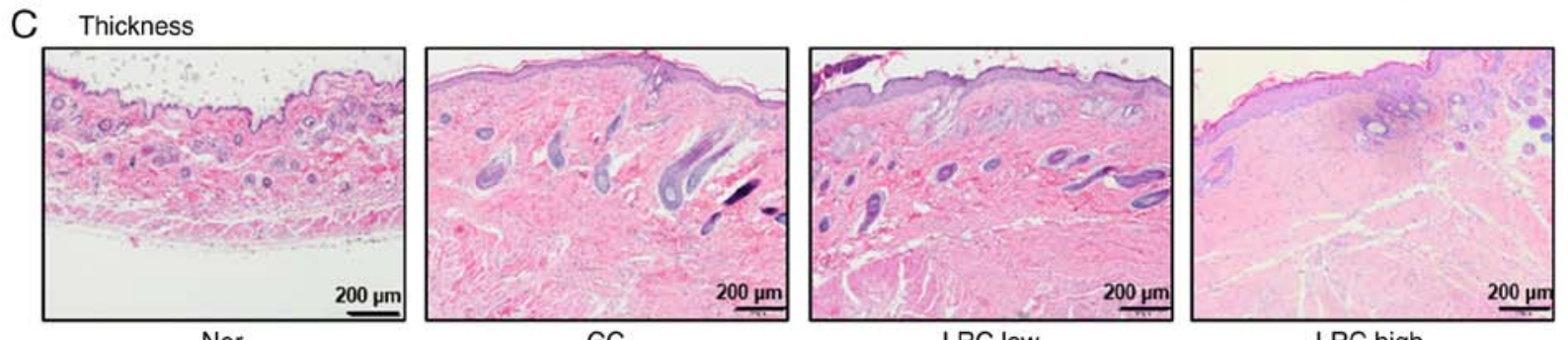

LRC low
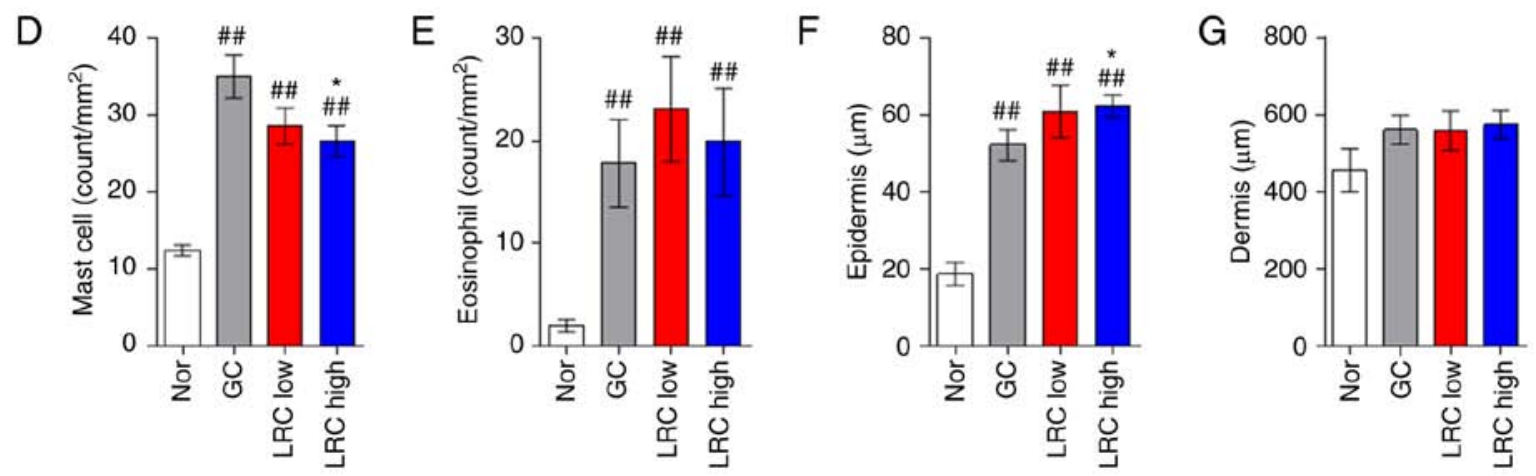

Figure 7. Effect of Lycii radicis cortex on 2,4-dinitrochlorobenzene-induced allergic contact dermatitis skin tissues. (A) Infiltration of mast cells was detected by toluidine blue staining (magnification, x200; scale bar size, $100 \mu \mathrm{m}$ ). (B) Eosinophil infiltration was detected by H\&E staining (magnification, $\mathrm{x} 400$; scale bar size, $50 \mu \mathrm{m}$ ). (C) The thickness of the epidermis and dermis was evaluated by H\&E staining of skin sections (magnification, x100; scale bar size, $200 \mu \mathrm{m}$ ). Measurement of the count of (D) mast cells and (E) eosinophils. All measurements were performed in five fields in each tissue. Measurement of the thickness of $(\mathrm{F})$ epidermis and $(\mathrm{G})$ dermis. All measurements were performed in three fields in each tissue. Data represent the mean \pm SEM. ${ }^{\# /} \mathrm{P}<0.01 \mathrm{vs}$. normal animals; ${ }^{\text {"P }}<0.05$ vs. GC animals. H\&E, hematoxylin and eosin. LRC, Lycii Radicis Cortex; ACD, allergic contact dermatitis; GC. glucocorticoids; GIOP, GC induced osteoporosis; DEX, dexamethasone; H\&E, hematoxylin and eosin stain.

MC3T3-E1 cells, which are known as osteoblast progenitor cells (24). DEX exhibited toxicity to the MC3T3-E1 cells; however, the cell survival rate was increased by LRC in a concentration-dependent manner (Fig. 8A and B). In addition, the expression of LDH in the cells which was increased by DEX was inhibited through LRC treatment (Fig. 8C) The expression levels of pro-apoptotic genes (caspase-6 and -9) were investigated by semi-quantitative RT-PCR. DEX increased the mRNA levels of both caspases, and DEX + LRC $(100 \mu \mathrm{g} / \mathrm{ml})$ decreased caspase- 6 and caspase-9 mRNA expression. DEX + LRC $(50 \mu \mathrm{g} / \mathrm{ml})$ and DEX + LRC $(100 \mu \mathrm{g} / \mathrm{ml})$ significantly increased the expression of $\mathrm{X}$-linked inhibitor of apoptosis protein (XIAP), and DEX + LRC $(100 \mu \mathrm{g} / \mathrm{ml})$ increased the expression of inhibitor of apoptosis protein (IAP)-1 and IAP-2 (Fig. 8D and E).

LRC prevents the GC-induced suppression of osteoblast differentiation via increasing BMP-2 and Runx2 protein expression. Alizarin Red S staining confirmed that DEX attenuated the formation of mineralized matrix areas in the MC3T3-E1 cells (Fig. 9A). Treatment with DEX significantly reduced the mineralization levels in MC3T3-E1 cells, and $\mathrm{LRC}$ at $100 \mu \mathrm{g} / \mathrm{ml}$ significantly inhibited this decrease. In addition, the absorbance values measured by extracting the 
Table II. Effect of LRC on the osteoporosis-related mediators in serum.

\begin{tabular}{lcccccc}
\hline Group & No. of mice & RANKL $(\mathrm{pg} / \mathrm{ml})$ & OPG $(\mathrm{ng} / \mathrm{ml})$ & SOST $(\mathrm{pg} / \mathrm{ml})$ & DKK1 $(\mathrm{ng} / \mathrm{ml})$ & FGF23 $(\mathrm{pg} / \mathrm{ml})$ \\
\hline Nor & 8 & $127.30 \pm 16.70$ & $5.92 \pm 0.43$ & $90.94 \pm 8.85$ & $65.06 \pm 8.34$ & $796.57 \pm 42.81$ \\
GIOP & 8 & $101.27 \pm 29.39$ & $10.96 \pm 1.16^{\mathrm{b}}$ & $257.24 \pm 84.09$ & $99.97 \pm 7.28^{\mathrm{a}}$ & $1321.40 \pm 280.14^{\mathrm{b}}$ \\
LRC low & 8 & $41.82 \pm 6.01^{\mathrm{b}}$ & $9.26 \pm 1.08^{\mathrm{b}}$ & $133.97 \pm 16.18^{\mathrm{a}}$ & $77.16 \pm 7.28$ & $1247.92 \pm 164.16^{\mathrm{a}}$ \\
LRC high & 8 & $46.82 \pm 8.53^{\mathrm{b}}$ & $9.66 \pm 1.10^{\mathrm{b}}$ & $150.52 \pm 32.90$ & $102.13 \pm 13.36^{\mathrm{a}}$ & $1162.78 \pm 76.91^{\mathrm{b}}$ \\
\hline
\end{tabular}

${ }^{\mathrm{a}} \mathrm{P}<0.05$ and ${ }^{\mathrm{b}} \mathrm{P}<0.01$ vs. normal animal GC animal; GIOP, glucocorticoids induced osteoporosis; LRC, Lycii radicis cortex; RANKL, receptor activator of nuclear factor $\kappa-B$ ligand; OPG, osteoprotegerin; SOST, sclerostin; DKK-1, Dickkopf WNT Signaling Pathway Inhibitor 1; FGF23, fibroblast growth factor 23 .

Table III. Effect of LRC on body and the organ weight.

\begin{tabular}{lccccccc}
\hline Group & No. of mice & Body weight $(\mathrm{g})$ & Liver $(\mathrm{g})$ & Testis $(\mathrm{g})$ & Thymus $(\mathrm{g})$ & Spleen $(\mathrm{g})$ & Kidney $(\mathrm{g})$ \\
\hline Nor & 8 & $39.54 \pm 0.78$ & $1.44 \pm 0.04$ & $0.24 \pm 0.01$ & $0.040 \pm 0.003$ & $0.13 \pm 0.01$ & $0.61 \pm 0.02$ \\
GIOP & 8 & $32.64 \pm 0.74^{\mathrm{b}}$ & $1.25 \pm 0.04^{\mathrm{b}}$ & $0.20 \pm 0.02$ & $0.014 \pm 0.001^{\mathrm{b}}$ & $0.10 \pm 0.01^{\mathrm{a}}$ & $0.58 \pm 0.02$ \\
LRC low & 8 & $32.75 \pm 0.79^{\mathrm{b}}$ & $1.32 \pm 0.08^{\mathrm{a}}$ & $0.24 \pm 0.01^{\mathrm{c}}$ & $0.012 \pm 0.001^{\mathrm{b}}$ & $0.07 \pm 0.01^{\mathrm{b}}$ & $0.59 \pm 0.02$ \\
LRC high & 8 & $31.65 \pm 0.77^{\mathrm{b}}$ & $1.31 \pm 0.08^{\mathrm{a}}$ & $0.24 \pm 0.01^{\mathrm{c}}$ & $0.013 \pm 0.002^{\mathrm{b}}$ & $0.08 \pm 0.01^{\mathrm{b}}$ & $0.57 \pm 0.02$ \\
\hline
\end{tabular}

${ }^{\mathrm{a}} \mathrm{P}<0.05$ and ${ }^{\mathrm{b}} \mathrm{P}<0.01$ vs. normal animal; ${ }^{\mathrm{C}}<0.05$ vs. GC animal; GIOP, glucocorticoids induced osteoporosis; LRC, Lycii radicis cortex.
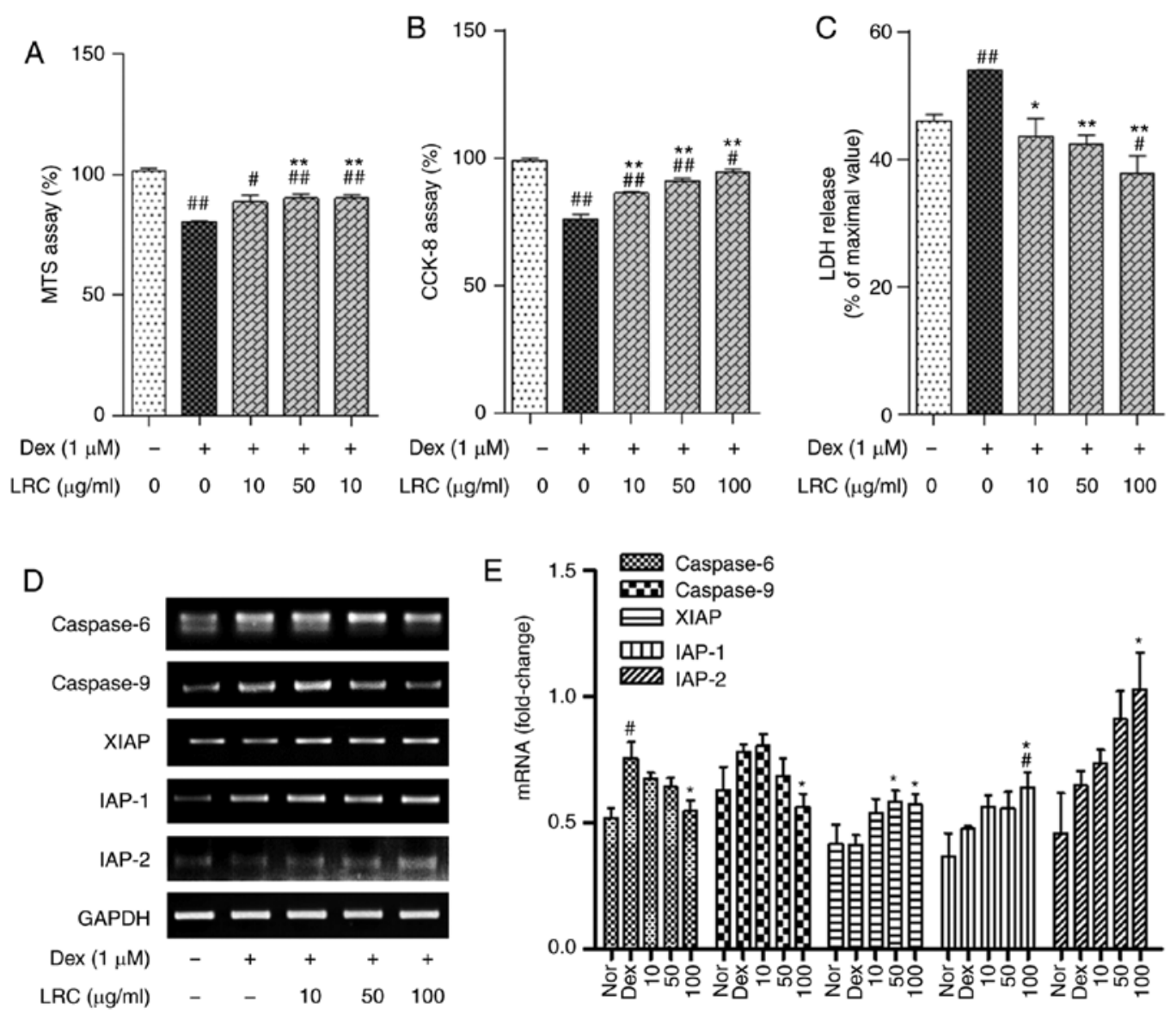

Figure 8. Effect of LRC on glucocorticoid-induced osteoblastic cells apoptosis. (A) MTS assay and (B) CCK-8 assay were used to evaluate the protective ability of LRC against cell death by DEX. The optical density value of the cells was measured using a spectrophotometer. (C) The effect of LRC on the expression of LDH induced by DEX was measured using an LDH assay kit. (D) mRNA level of apoptosis indicators, including caspase-6, caspase-9, X-linked inhibitor of apoptosis protein, IAP-1 and IAP-2. (E) Each indicator was quantified through GAPDH. Data represent the means \pm SEM of three independent experiments. ${ }^{\#} \mathrm{P}<0.05$ and ${ }^{\# \#} \mathrm{P}<0.05$ vs. untreated cells; ${ }^{*} \mathrm{P}<0.05$ and ${ }^{* *} \mathrm{P}<0.01$ vs. DEX-treated cells. LRC, Lycii radicis cortex; DEX, dexamethasone; LDH, lactate dehydrogenase; IAP, inhibitor of apoptosis protein. 
A
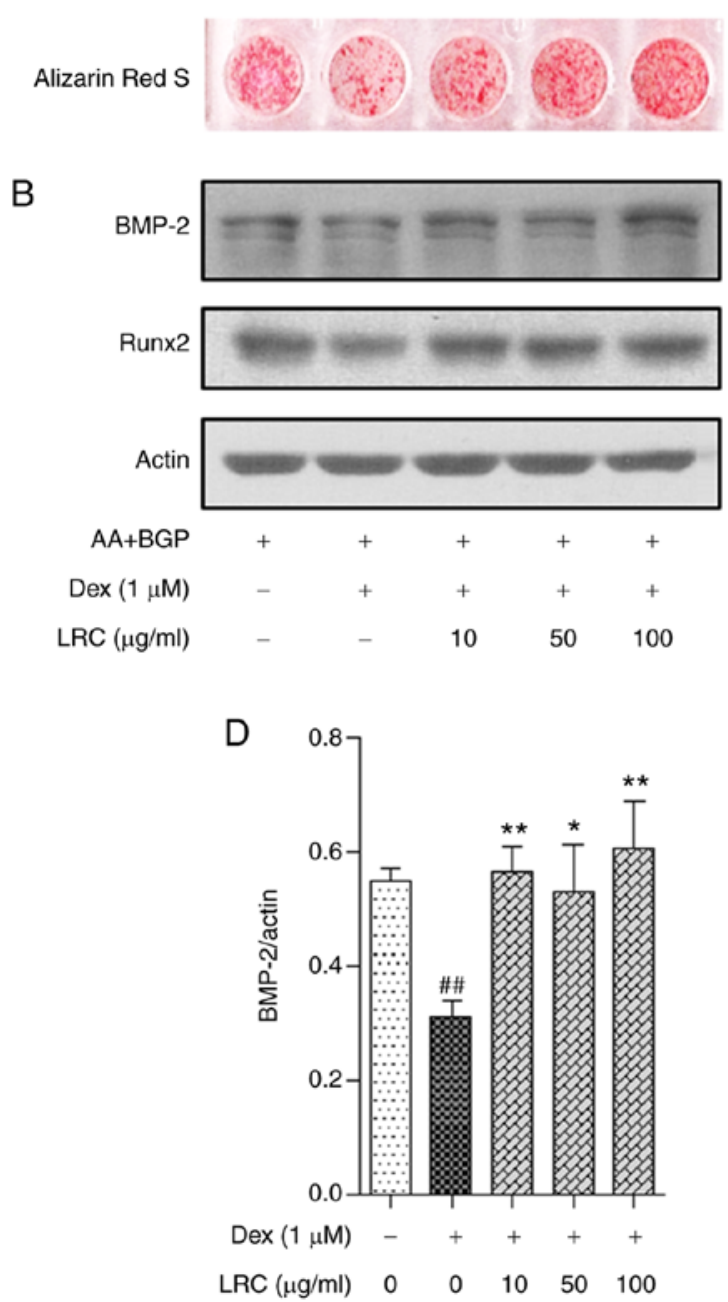

C

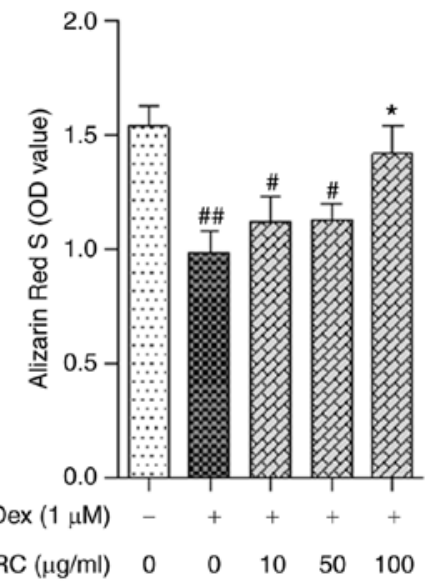

$\mathrm{E}$

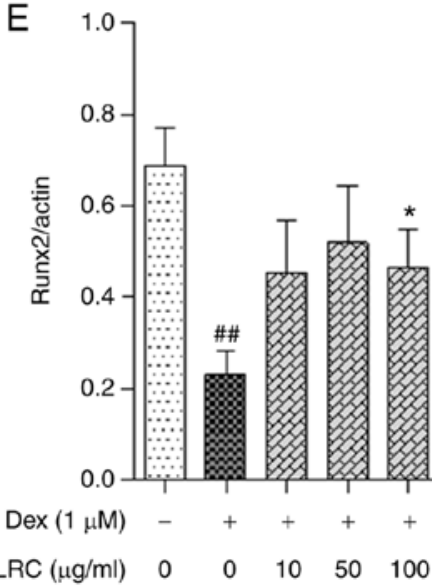

Figure 9. Effect of LRC on osteoblast mineralization and differentiation factors in vitro. (A) Alizarin Red S staining was performed on a 24-well plate for $<21$ days with osteogenic differentiation $\alpha$-MEM containing DEX $(1 \mu \mathrm{M})$ in the presence of varying concentrations of LRC in MC3T3-E1 cells. (B) The effect of LRC on the mineralization factors BMP-2 and Runx 2 was investigated by western blot analysis. (C) The absorbance wavelength value was measured using a spectrophotometer. (D and E) The effect of LRC on BMP-2 and Runx2 expression was verified using ImageJ software. Data represent the means \pm SEM of three independent experiments. ${ }^{\#} \mathrm{P}<0.05,{ }^{\# \#} \mathrm{P}<0.01$ vs. untreated cells; ${ }^{*} \mathrm{P}<0.05,{ }^{* *} \mathrm{P}<0.01$ vs. DEX-treated cells. LRC, Lycii radicis cortex; DEX, dexamethasone; Runx2, Runt-related transcription factor 2; BMP-2, bone morphogenetic protein 2.

dye revealed similar results (Fig. 9C). The protein expression levels of BMP-2 and Runx2 were also measured (Fig. 9B). The results revealed that DEX + LRC $(100 \mu \mathrm{g} / \mathrm{ml})$ increased the expression levels of BMP-2 and Runx2, which were inhibited by DEX at the protein level (Fig. 9D and E).

Effect of LRC on mRNA expression of factors associated with the GC-induced suppression of osteoblast differentiation of MC3T3-E1 cells. To evaluate the effects of LRC on the expression of osteogenic differentiation-related gene markers, cells were treated with DEX + LRC under osteogenic differentiation conditions for 4 days. Osteoblastic differentiation was measured by semi-quantitative RT-PCR. The mRNA expression levels of Runx2, alkaline phosphatase (ALP) and osteocalcin $(\mathrm{OCN})$ were significantly reduced by DEX treatment (Fig. 10A-D). However, there was no significant effect on the expression of OSN or collagen type I $\alpha 1$ (Colla1) (Fig. 10A, $\mathrm{F}$ and $\mathrm{G})$. As a result of normalizing the expression of these genes to GAPDH, LRC significantly increased the mRNA expression of osteoblastic differentiation markers compared with that of the DEX-treated cells (Fig. 10).
Effect of LRC on GC-induced resistance in macrophages. Macrophages play an important role in immunity and immune responses (25). In the present study, LRC or DEX + LRC did not exert any toxicity on RAW 264.7 macrophage cells (Fig. 11A and B). DEX significantly inhibited the $\mathrm{p}-\mathrm{NF}-\kappa \mathrm{B}$ levels at $2 \mathrm{~h}$, while DEX decreased $\mathrm{p}-\mathrm{NF}-\kappa \mathrm{B}$ expression at $24 \mathrm{~h}$, although the difference was not significant. When LRC was co-treated with DEX, it inhibited $\mathrm{p}-\mathrm{NF}-\kappa \mathrm{B}$ at both 2 and $24 \mathrm{~h}$ (Fig. 11C and D). GC resistance is considered the main cause of the GC-induced side-effects (26). In the present study, treatment with DEX increased the expression of $\mathrm{p}-\mathrm{GR}$ at $2 \mathrm{~h}$ (Fig. 11E and G). LRC also increased the levels of p-GR. However, at $24 \mathrm{~h}$ (long-term), the expression of p-GR decreased at $<2$ h due to GC resistance. DEX + LRC prevented this inhibition of p-GR expression in the long-term (Fig. 11F and $\mathrm{H}$ ). $\mathrm{p}-\mathrm{NF} \mathrm{kB}$ was also identified as an inflammatory mediator that was associated with the inhibitory effect of DEX + LRC on p-GR resistance.

Identification of LRC through GC/MS analysis. Scopoletin has been reported to be a constituent compound of LRC (27). 
A
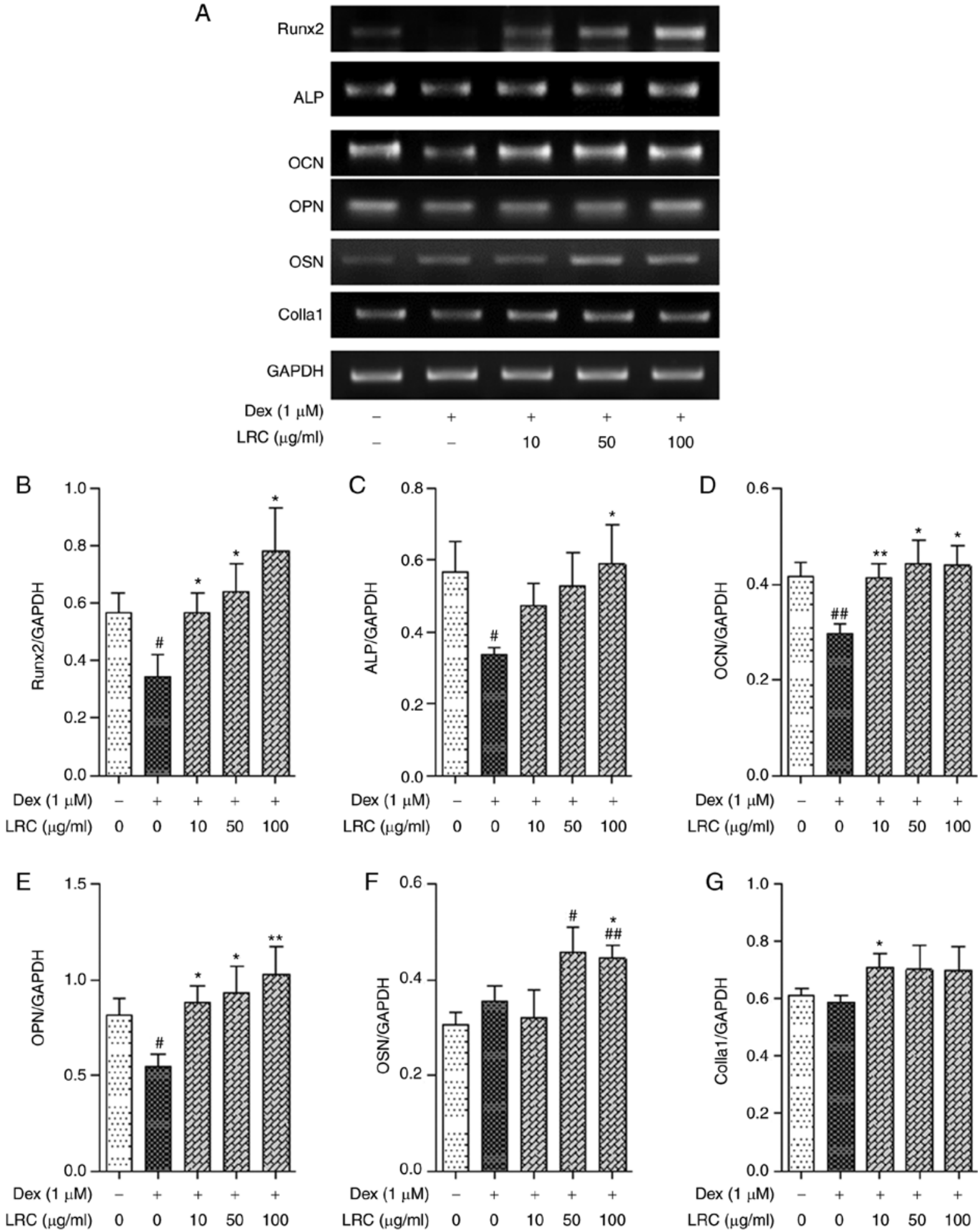

Figure 10. Effect of LRC on osteogenic factors associated with osteoblast differentiation mRNA expression in vitro. MC3T3-E1 cells were cultured in osteogenic differentiation $\alpha$-MEM containing DEX and LRC for 4 days. (A) The expression of osteoblast-related genes was analyzed through semi-quantitative RT-PCR. The expression of (B) Runx2, (C) ALP, (D) OCN, (E) OPN, (F) OSN and (G) Colla1was normalized by GAPDH. Data represent the means \pm SEM of three independent experiments. ${ }^{\# P} \mathrm{P}<0.05,{ }^{\# \#} \mathrm{P}<0.01$ vs. untreated cells; ${ }^{*} \mathrm{P}<0.05,{ }^{* *} \mathrm{P}<0.01$ vs. DEX-treated cells. LRC, Lycii radicis cortex; DEX, dexamethasone; RT-PCR, reverse transcription-PCR; Runx2, runt-related transcription factor 2; ALP, alkaline phosphatase; OCN, osteocalcin; OPN, osteopontin; OSN, osteonectin; Colla1, collagen type I $\alpha 1$.

In the present study, GC/MS analysis revealed that scopoletin was detected in the LRC water extract, and the results were compared with scopoletin standard to confirm that the peaks matched (Fig. 12).

\section{Discussion}

Inflammatory diseases, including allergic dermatitis, are treated with GC prescriptions (28). Despite their side-effects, GCs are 

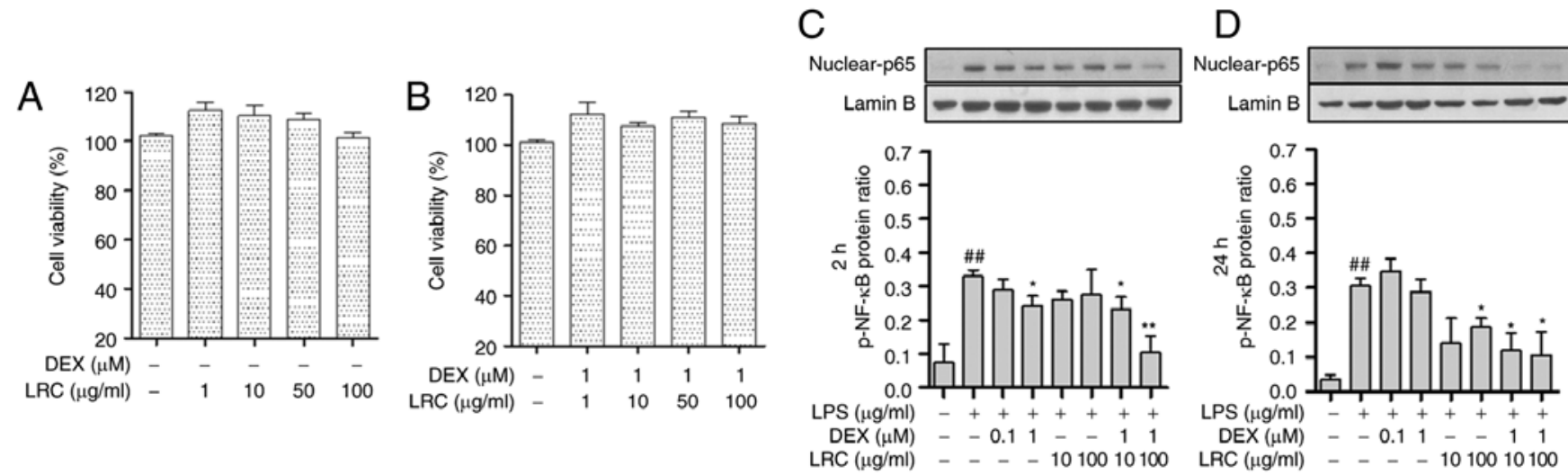

$\mathrm{F}$
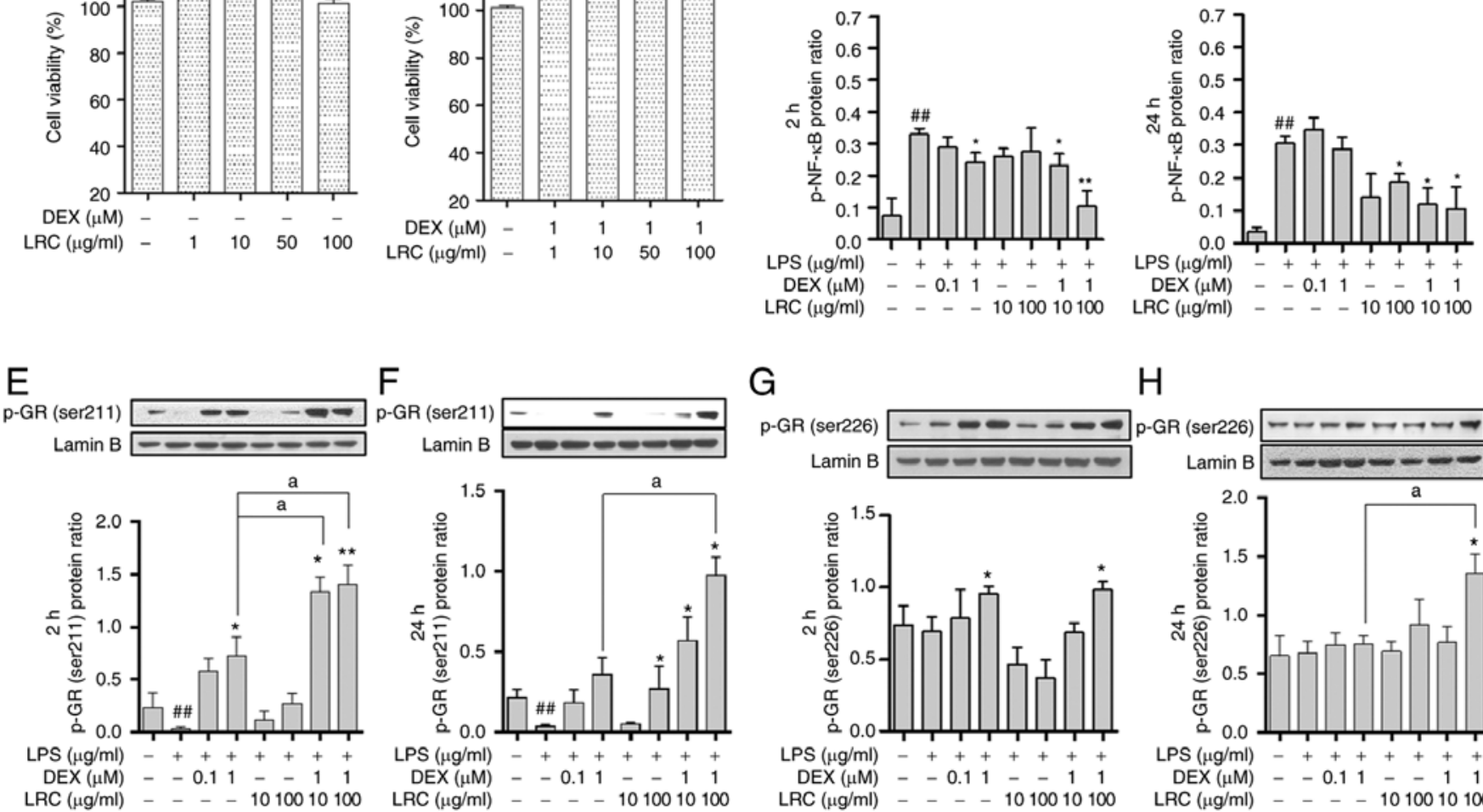

$$
\text { Lamin B }
$$

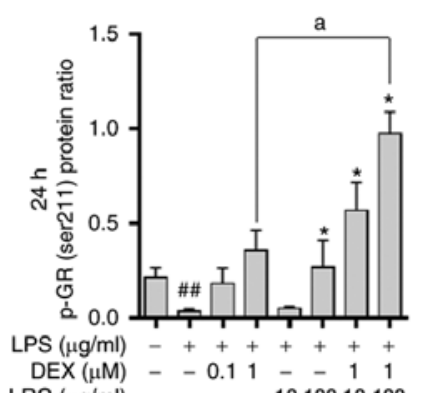

G

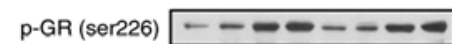

$\mathrm{H}$ Lamin B $---\infty-\infty-\infty$

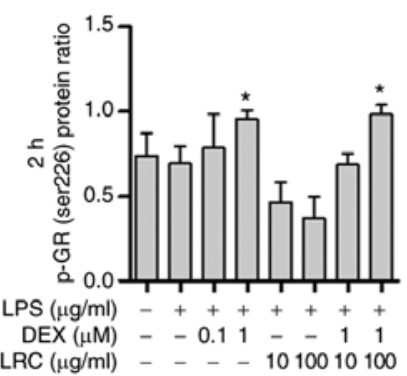

p-GR (ser226)
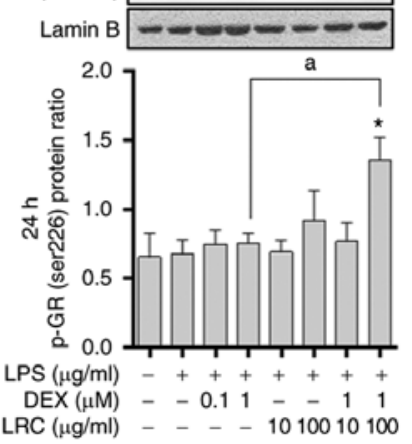

Figure 11. Anti-inflammatory effect of LRC through nuclear p-GR regulation on macrophages. (A and B) Neither LRC nor DEX + LRC have toxicity to RAW 264.7 cells. RAW 264.7 cells were cultured overnight and incubated with various doses of LRC or DEX + LPS for 2 or 24 h. The graph and bands represent the protein levels of $(\mathrm{C}$ and $\mathrm{D}) \mathrm{p}-\mathrm{NF}-\kappa \mathrm{B},(\mathrm{E}$ and $\mathrm{F}) \mathrm{p}-\mathrm{GR}$ Ser211 and $(\mathrm{G}$ and $\mathrm{H}) \mathrm{p}-\mathrm{GR}$ Ser226 compared with those of lamin B. Data represent the mean \pm SEM of $>3$ independent experiments. ${ }^{\# \#} \mathrm{P}<0.01$ vs. untreated cells; ${ }^{*} \mathrm{P}<0.05,{ }^{* *} \mathrm{P}<0.01$ vs. LPS-treated cells; ${ }^{\text {a }}<0.05$ vs. DEX treated cells. LRC, Lycii radicis cortex; DEX, dexamethasone; GR, glucocorticoid receptor; p, phosphorylated.

prescribed as a treatment for the majority of allergic dermatitis cases as GC topical treatment is effective and has a low cost (29). Although patients with ACD are being treated with GC under strict guidelines, there is still a high risk of GIOP $(30,31)$. Despite extensive research on GIOP, previous models were induced without the underlying disease, which may not reflect the actual situation of the patient. Therefore, the present study compared GC-treated mice with ACD and GC-treated mice without ACD. In the present study, a GIOP model was established in the case of ACD being the underlying disease as a precondition of secondary osteoporosis for depicting the patients' condition. The results revealed that GIOP did not occur in the absence of the underlying disease, ACD. This differs from previously published reports stating that DEX decreased BMD in mice $(32,33)$. However, other studies have reported that DEX increases the bone progenitor ability of bone progenitor cells in vitro $(34,35)$. The difference between these results may be due to a variety of reasons, including the concentration of DEX used in the study or the duration of the experiment. The present study found that LRC had an effect on GIOP and also proved to enhance immunity against DEX application, when administered orally, as in the treatment of clinical patients. Overall, the results of the present study suggest that the use of LRC alleviates the side-effects of GCs.

Osteoporosis is a typical side-effect of GCs, where the bone quality decreases due to changes in bone density and microstructure (36). The qualitative increase in cancellous bone structures such as Tb.Sp, Tb.N and BS/TV along with the increase in bone mass through BMD and BV/TV is important. In the present study, LRC significantly suppressed the loss of bone density induced by DEX, and led to a qualitative improvement of various bone microstructures. These results suggest that LRC can attenuate GIOP. Calcium is the most important mineral for bone formation and for maintaining the skeleton. Calbindin-D28k, a calcium-binding protein, is known to be an important factor for calcium metabolism and absorption of calcium by metabolic organs such as the duodenum and kidney $(37,38)$. It has been demonstrated calbindin-D28k is produced by osteoblastic cells, and protects osteoblasts from apoptosis (39). Therefore, calbindin-D28k is expected to play an important role in the mechanism leading to secondary osteoporosis. In a previous study by the authors, the expression of calbindin-D28k was observed in the duodenum and kidneys of mice (40). In the present study, IHC analysis of calbindin-D28k expression in kidney and duodenal tissue revealed that LRC increased the calcium-absorbing ability which was decreased by DEX. These results indicate that LRC is involved in the protein-mediated mechanism of calcium-absorption associated with the inhibition of osteoblast death.

In addition, the present study aimed to verify whether LRC interferes with the anti-inflammatory effects of DEX in an 

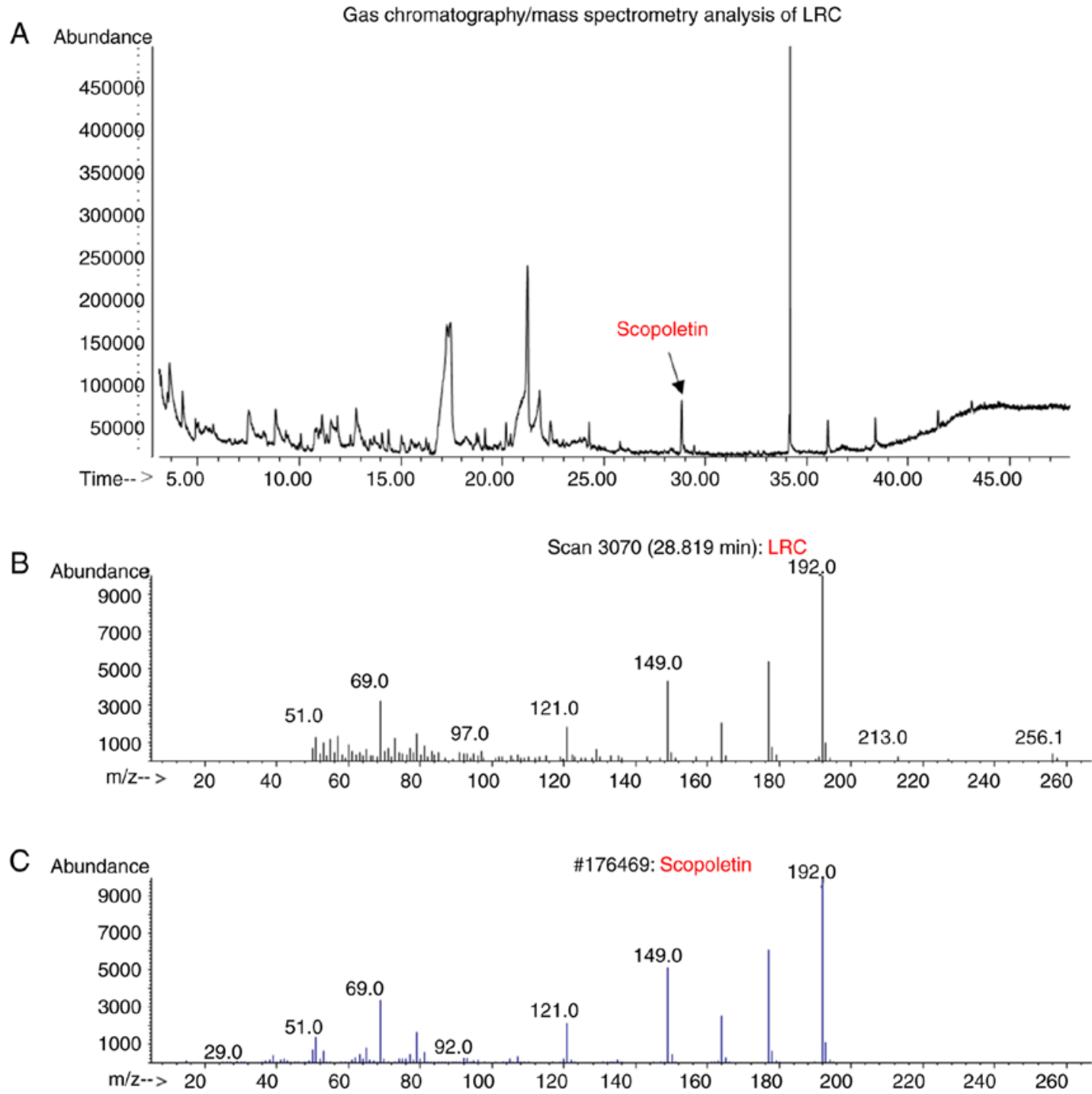

Figure 12. Identification of LRC through GC/MS analysis. (A) Analysis of LRC extract by GC/MS identified scopoletin, which is known as an active ingredient of LRC, with a peak of 28.819 min retention time. (B and C) The mass spectrum of this peak was found to be $98 \%$ consistent with that of scopoletin according to the Wiley database. It was concluded that the LRC extract contained scopoletin. LRC, Lycii radicis cortex; GC/MS, gas chromatography/mass spectrometry.

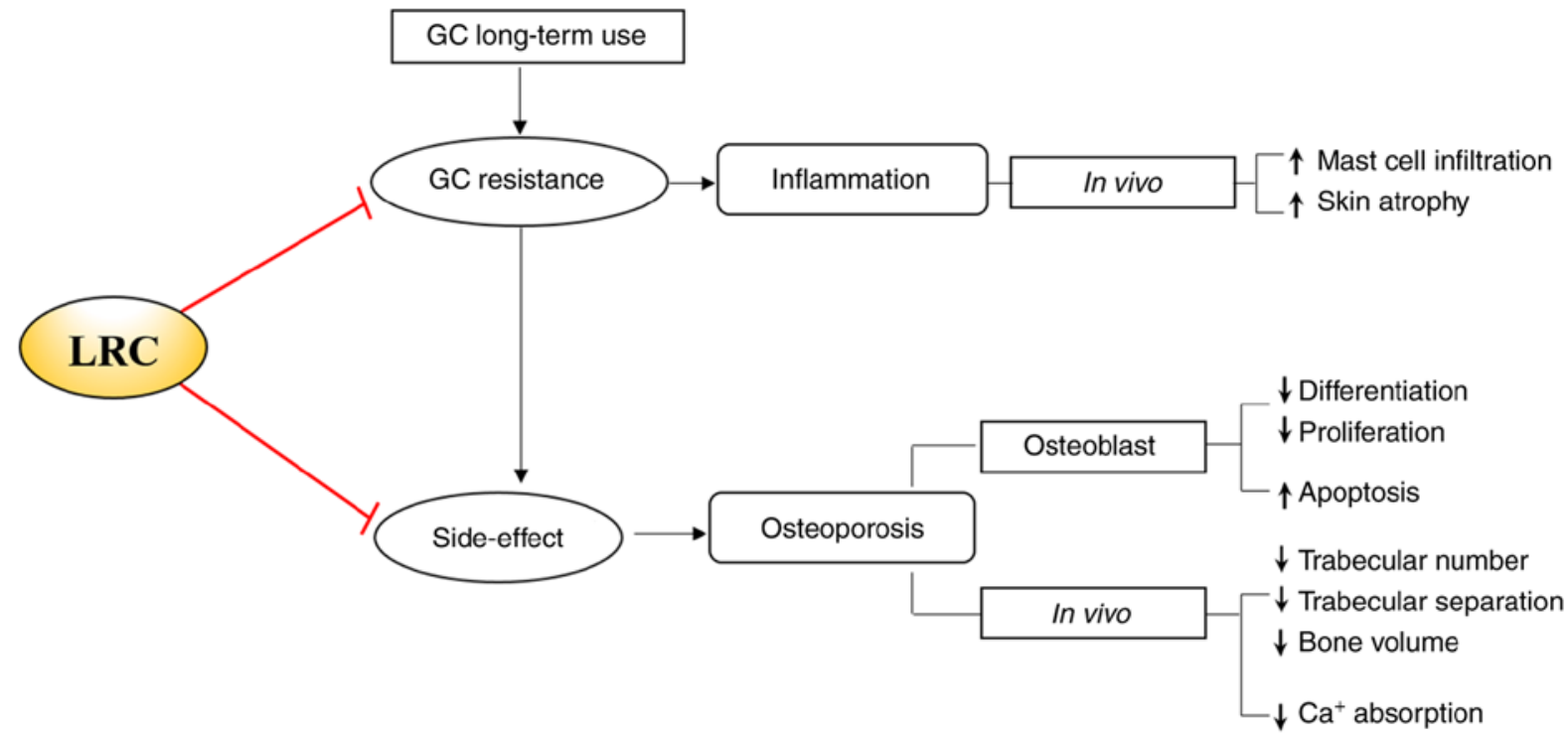

Figure 13. Schematic diagram of the inhibitory effect of Lycii radicis cortex on the induction of resistance and osteoporosis caused by long-term glucocorticoid use. 
ACD model. LRC was used along with DEX to demonstrate that LRC complemented the effects of DEX and decreased its side-effects in vivo and in vitro. Mast cells can release inflammatory mediators and cytokines for participating in inflammatory reactions such as flushing, itching and swelling (41). In previous animal experiments, mast cells were more significantly reduced by DEX + LRC than by DEX only, and the eosinophil infiltration number was maintained by treatment with LRC + DEX compared with that of DEX treatment alone. Epidermis and dermis atrophy are side-effects of GCs (42). In the present study, LRC significantly reduced dermis atrophy. LRC usage combined with DEX did not interfere with the anti-inflammatory effects of DEX. This suggests that the experimental combination of existing drugs and herbal medicines may be able to show synergy and may have a valuable potential.

Long-term DEX use has been reported to lead to the up-regulation of caspases-3, -6 and -9, which in turn leads to the apoptosis of osteoblasts (43). Prevention of osteoblast apoptosis is an important mechanism in the pathogenesis of secondary osteoporosis. In the present study, LRC inhibited caspase- 6 and -9 expression. Caspase- 6 is an initiator of the caspase pathway, which is involved in mitochondrial damage (44). The activation of caspase- 9 is inhibited by members of the IAP family, including XIAP (45). Caspase-6, an effector caspase that is activated by caspase- 9 in the apoptosome, can also be blocked by XIAP (46). The relative expression level of XIAP is one of the main factors regulating mitochondrial apoptosis downstream processes (47). According to previous studies, DEX increases the protein levels of caspase-6, caspase-9 and MC3T3-E1, suggesting that DEX is involved in apoptosis $(16,44)$. In the present study, LRC decreased the levels of caspase- 6 and -9 that were induced by DEX. Furthermore, LRC increased the levels of XIAP and IAPs. These results indicate that LRC inhibits osteoblast apoptosis induced by DEX through a caspase-mediated mechanism.

The reduction in bone formation due to the death of osteoblasts causes an imbalance in bone metabolism with osteoclasts, resulting in osteoporosis. Therefore, it is important to determine the expression of bone-forming factors, such as BMP-2, Runx2, ALP, OCN, osteopontin (OPN), osteonectin (OSN) and Colla1, along with apoptotic markers (48). Initially, osteoblasts actively proliferate to produce type I collagen extracellular matrix (49). The expression of ALP is enhanced immediately following the proliferation period, and mineralization begins, which results in an increased expression of OCN and OPN (49). The expression of the OCN and ALP genes is known to be stimulated by BMP-2 $(50,51)$. Runx 2 is a transcription factor, and its activity is increased by BMP-2 signaling (51). Runx2 binds to osteogenic genes to regulate the expression of Colla1, OPN and OCN (a late bone differentiation marker) (52). In the present study, LRC improved the osteoblast mineralization inhibited by DEX, and it also increased the expression of Runx2, BMP-2, ALP, OCN, OPN, OSN and Colla1, which are involved in osteoblast mineralization and differentiation. These results demonstrate that LRC increases the differentiation of osteoblasts inhibited by DEX through a Runx2- and BMP-2-mediated mechanism. This confirms the effect of LRC, and the osteoblast differentiation effect of LRC was demonstrated through the indicators of the exact mechanism (16). The results of osteoblast differentiation and death in vitro were consistent with the results of the animal experiments, which suggests that combined treatment with DEX and LRC inhibited osteoporosis in animals through the inhibition of osteoblast apoptosis and differentiation.

$\mathrm{GC}$ resistance is the cause of GC-associated side-effects, since GC resistance leads to an increase in the length of GC treatment and in the dose of GCs (9). GR is known to be the main factor of the GC resistance mechanism $(9,10)$. To investigate the effects of LRC on GC resistance, the authors performed GR Ser-211 and GR Ser-226 protein expression experiments in macrophages, which are innate immune cells that play a central role in the inflammatory response (26). The sensitivity of GR is closely associated with GC resistance. $\mathrm{GC}$ binds to ligands to activate receptors, and the complex is translocated from the cytoplasm to the nucleus $(53,54)$. GR regulates gene expression by interacting with transcription factors and NF- $\mathrm{NB}$, and the majority of these mechanisms have anti-inflammatory actions (55). Furthermore, negative GR elements (GREs), across the site of transcription, can regulate the functions of bone (mediated by OCN), skin (via keratins) and inflammation (56). A reduction in the receptor's affinity to the ligand is mainly responsible for GC resistance (57). The reason for this reduced affinity is suspected to be: i) Delayed or failed translocation of the GC-GR complex to the nucleus; and ii) decreased transcriptional activity due to decreased GRE binding (57). The phosphorylation sites of GR are Ser203, Ser211 and Ser226, where the numbers refer to the numbering scheme of the N-terminal transcriptional regulatory domain of human GR. Previous studies have reported that p-GR Ser211 and Ser226 (but not Ser203) appear to contribute to gene transcriptional responses to GCs $(58,59)$. The results of the present demonstrated that LRC increased the expression of $\mathrm{p}-\mathrm{GR}$ transcribed in the nucleus via the GC response. In addition, it was observed that LRC increased and maintained the expression p-GR, which was decreased by GC resistance caused by the CG long-term response. These results suggest that LRC exerts a positive effect on GC resistance. Therefore, LRC supports subsequent regulatory immune responses. The increased p-GR expression effect of LRC inhibits GC resistance, which is the cause of GC side-effects; however, it is unclear whether this result directly affects secondary osteoporosis. Therefore, further studies are required to compare the anti-inflammatory effects of DEX at a high dose without LRC with those of DEX at a low dose with LRC.

The present study has the following limitations: There was no experimental group treated only with DNCB. Thus, the question of whether osteoporosis can be induced by treatment with DNCB alone may be reconsidered. To eliminate this concern, it is necessary to demonstrate in future studies whether osteoporosis is induced by treatment with DNCB alone for a long period of time. In addition, the present study considered that atrophy of the skin occurred due to long-term DEX treatment. Previous studies have indicated that when GC is applied to mice for 18 days (60), skin atrophy similar to that of humans is found. Since the present study applied DEX for a much longer period (namely 8 weeks), it can be considered that the skin exhibited side-effects. In the future, these claims should be verified by comparing DNCB-only treatment and DEX treatment groups. 
In conclusion, the present study focused on the possibility that herbal medicines could overcome the side-effects of GCs and may become a complete replacement for GC treatment. The present study identified the method that was most suitable for secondary osteoporosis animal models. The results of the present study are meaningful in establishing and demonstrating the value of the combination of herbal medicine and GC. The present results revealed that LRC inhibited osteoblast apoptosis induced by DEX and increased the levels of osteoblast differentiation-related genes. LRC also significantly reduced GIOP as a side-effect of DEX, while maintaining its anti-inflammatory effects. This suggests that LRC has the potential to be used and developed as a drug to relieve the side-effects of GCs and to maximize their effectiveness in combination with DEX (Fig. 13).

\section{Acknowledgements}

Not applicable.

\section{Funding}

The present study was supported by Basic Science Research Program through the National Research Foundation of Korea (NRF) funded by the Ministry of Education (NRF-2020R1A6A3A01098984 and no.2020R1A2C1007836).

\section{Availability of data and materials}

All data generated or analyzed during this study are included in this published article.

\section{Authors' contributions}

YS and JHK conceptualized the study. BL performed all the experiments. MK, EYK, HJP and HSJ contributed to the statistical analysis. SH, MK, HJP and HSJ assisted with the interpretation of the results. BL drafted the manuscript. BL and JHK confirm the authenticity of all the raw data. All authors have read and approved the final manuscript.

\section{Ethics approval and consent to participate}

All animal experiments were approved by the Kyung Hee University Animal Care and Use Committee [KHUASP(SE)-17-082].

\section{Patient consent for publication}

Not applicable.

\section{Competing interests}

The authors declare that they have no competing interests.

\section{References}

1. Frenkel B, White W and Tuckermann J: Glucocorticoid-induced osteoporosis. Adv Exp Med Biol 872: 179-215, 2015.

2. Henneicke H, Gasparini SJ, Brennan-Speranza TC, Zhou H and Seibel MJ: Glucocorticoids and bone: Local effects and systemic implications. Trends Endocrinol Metab 25: 197-211, 2014.
3. Mirza F and Canalis E: Management of endocrine disease: Secondary osteoporosis: pathophysiology and management. Eur J Endocrinol 173: R131-151, 2015.

4. Tuck S and Francis R: Testosterone, bone and osteoporosis. Front Horm Res 37: 123-132, 2009.

5. Briot K and Roux C: Glucocorticoid-induced osteoporosis. RMD Open 1: e000014, 2015.

6. Shen C, Chen F, Zhang Y, Guo Y and Ding M: Association between use of antiepileptic drugs and fracture risk: A systematic review and meta-analysis. Bone 64: 246-253, 2014.

7. Moura C, Bernatsky S, Abrahamowicz M, Papaioannou A Bessette L, Adachi J, Goltzman D, Prior J, Kreiger N, Towheed T, et al: Antidepressant use and 10-year incident fracture risk: The population-based Canadian Multicentre Osteoporosis Study (CaMoS). Osteoporos Int 25: 1473-1481, 2014.

8. Van Staa TP, Leufkens HG, Abenhaim L, Zhang B and Cooper C: Use of oral corticosteroids and risk of fractures. J Bone Miner Res 15: 993-1000, 2000

9. Barnes PJ and Adcock IM: Glucocorticoid resistance in inflammatory diseases. Lancet 373: 1905-1917, 2009.

10. Schaaf MJ and Cidlowski JA: Molecular mechanisms of glucocorticoid action and resistance. J Steroid Biochem Mol Biol 83: 37-48, 2002.

11. Xie LW, Atanasov AG, Guo DA, Malainer C, Zhang JX, Zehl M, Guan SH, Heiss EH, Urban E, Dirsch VM and Kopp B: Activity-guided isolation of NF- $\kappa \mathrm{B}$ inhibitors and PPAR $\gamma$ agonists from the root bark of Lycium chinense Miller. J Ethnopharmacol 152: 470-477, 2014.

12. Gao D, Li Q, Liu Z, Li Y, Liu Z, Fan Y, Li K, Han Z and Li J: Hypoglycemic effects and mechanisms of action of Cortex Lycii Radicis on alloxan-induced diabetic mice. Yakugaku Zasshi 127: 1715-1721, 2007.

13. Kim JH, Kim EY, Lee B, Min JH, Song DU, Lim JM, Eom JW, Yeom M, Jung HS and Sohn Y: The effects of Lycii Radicis Cortex on RANKL-induced osteoclast differentiation and activation in RAW 264.7 cells. Int J Mol Med 37: 649-658, 2016.

14. Park E, Jin HS, Cho DY, Kim J, Kim MC, Choi CW, Jin Y, Lee JW, Park JH, Chung YS, et al: The effect of Lycii Radicis Cortex extract on bone formation in vitro and in vivo. Molecules 19: 19594-19609, 2014.

15. Park E, Kim J, Kim MC, Yeo S, Kim J, Park S, Jo M, Choi CW, Jin HS, Lee SW, et al: Anti-osteoporotic effects of kukoamine B Isolated from Lycii radicis cortex extract on osteoblast and osteoclast cells and ovariectomized osteoporosis model mice. Int J Mol Sci 20: 2784, 2019

16. Kim J, Lee H, Kang KS, Chun KH and Hwang GS: Protective effect of Korean Red Ginseng against glucocorticoid-induced osteoporosis in vitro and in vivo. J Ginseng Res 39: 46-53, 2015.

17. Ma Y, Yang $\mathrm{H}$ and Huang J: Icariin ameliorates dexamethasone-induced bone deterioration in an experimental mouse model via activation of microRNA186 inhibition of cathepsin K. Mol Med Rep 17: 1633-1641, 2018.

18. Kim EY, Kim JH, Kim M, Park JH, Sohn Y and Jung HS: Abeliophyllum distichum Nakai alleviates postmenopausal osteoporosis in ovariectomized rats and prevents RANKL-induced osteoclastogenesis in vitro. J Ethnopharmacol 257: 112828, 2020.

19. Kim M, Kim HS, Kim JH, Kim EY, Lee B, Lee SY, Jun JY, Kim MB, Sohn Y and Jung HS: Chaenomelis fructus inhibits osteoclast differentiation by suppressing NFATc1 expression and prevents ovariectomy-induced osteoporosis. BMC Complement Med Ther 20: 35, 2020.

20. Kim JH, Kim M, Jung HS and Sohn Y: Leonurus sibiricus L. ethanol extract promotes osteoblast differentiation and inhibits osteoclast formation. Int J Mol Med 44: 913-926, 2019.

21. Konappa N, Udayashankar AC, Krishnamurthy S, Pradeep CK, Chowdappa S and Jogaiah S: GC-MS analysis of phytoconstituents from Amomum nilgiricum and molecular docking interactions of bioactive serverogenin acetate with target proteins. Sci Rep 10: 16438, 2020.

22. Zhang EY, Chen AY and Zhu BT: Mechanism of dinitrochlorobenzene-induced dermatitis in mice: Role of specific antibodies in pathogenesis. PLoS One 4: e7703, 2009.

23. Park G, Kim HG, Lim S, Lee W, Sim Y and Oh MS: Coriander alleviates 2,4-dinitrochlorobenzene-induced contact dermatitis-like skin lesions in mice. J Med Food 17: 862-868, 2014.

24. Hiura K, Sumitani K, Kawata T, Higashino K, Okawa M, Sato T, Hakeda Y and Kumegawa M: Mouse osteoblastic cells (MC3T3-E1) at different stages of differentiation have opposite effects on osteoclastic cell formation. Endocrinology 128: 1630-1637, 1991. 
25. Elhelu MA: The role of macrophages in immunology. J Natl Med Assoc 75: 314-317, 1983.

26. van Rossum EF and Lamberts SW: Glucocorticoid resistance syndrome: A diagnostic and therapeutic approach. Best Pract Res Clin Endocrinol Metab 20: 611-626, 2006.

27. Potterat O: Goji (Lycium barbarum and L. Chinense): Phytochemistry, pharmacology and safety in the perspective of traditional uses and recent popularity. Planta Med 76: 7-19, 2010.

28. Moghadam-Kia S and Werth VP: Prevention and treatment of systemic glucocorticoid side effects. Int J Dermatol 49: 239-248, 2010.

29. Lagos BR and Maibach HI: Frequency of application of topical corticosteroids: An overview. Br J Dermatol 139: 763-766, 1998

30. HaeckI,van Velsen S, de Bruin-Weller Mand Bruijnzeel-Koomen C: Bone mineral density in patients with atopic dermatitis. Chem Immunol Allergy 96: 96-99, 2012.

31. Garg NK and Silverberg JI: Eczema is associated with osteoporosis and fractures in adults: A US population-based study. J Allergy Clin Immunol 135: 1085-1087 e2, 2015.

32. Zhang J, Song J and Shao J: Icariin attenuates glucocorticoid-induced bone deteriorations, hypocalcemia and hypercalciuria in mice. Int J Clin Exp Med 8: 7306-7314, 2015.

33. Fan S, Gao X, Chen P and Li X: Myricetin ameliorates glucocorticoid-induced osteoporosis through the ERK signaling pathway. Life Sci 207: 205-211, 2018.

34. Shalhoub V, Conlon D, Tassinari M, Quinn C, Partridge N, Stein GS and Lian JB: Glucocorticoids promote development of the osteoblast phenotype by selectively modulating expression of cell growth and differentiation associated genes. J Cell Biochem 50: 425-440, 1992

35. Igarashi M, Kamiya N, Hasegawa M, Kasuya T, Takahashi T and Takagi M: Inductive effects of dexamethasone on the gene expression of Cbfa1, Osterix and bone matrix proteins during differentiation of cultured primary rat osteoblasts. J Mol Histol 35: 3-10, 2004

36. Parkinson IH and Fazzalari NL: Interrelationships between structural parameters of cancellous bone reveal accelerated structural change at low bone volume. J Bone Miner Res 18 2200-2205, 2003.

37. Kutuzova GD, Akhter S, Christakos S, Vanhooke J, Kimmel-Jehan C and Deluca HF: Calbindin D(9k) knockout mice are indistinguishable from wild-type mice in phenotype and serum calcium level. Proc Natl Acad Sci USA 103: 12377-12381, 2006.

38. Christakos S, Gabrielides Cand Rhoten WB: Vitamin D-dependent calcium binding proteins: Chemistry, distribution, functional considerations, and molecular biology. Endocr Rev 10: 3-26, 1989.

39. Bellido T, Huening M, Raval-Pandya M, Manolagas SC and Christakos S: Calbindin-D28k is expressed in osteoblastic cells and suppresses their apoptosis by inhibiting caspase-3 activity. J Biol Chem 275: 26328-26332, 2000.

40. Kim MH, Lee GS, Jung EM, Choi KC, Oh GT and Jeung EB Dexamethasone differentially regulates renal and duodenal calcium-processing genes in calbindin-D9k and -D28k knockout mice. Exp Physiol 94: 138-151, 2009.

41. Church MK and Levi-Schaffer F: The human mast cell. J Allergy Clin Immunol 99: 155-160, 1997.

42. Schoepe S, Schacke H, May E and Asadullah K: Glucocorticoid therapy-induced skin atrophy. Exp Dermatol 15: 406-420, 2006.

43. Ji YZ, Geng L, Zhou HB, Wei HC and Chen HD: Chinese herbal medicine Yougui Pill reduces exogenous glucocorticoid-induced apoptosis in anterior pituitary cells. Neural Regen Res 11: 1962-1968, 2016

44. Chua CC, Chua BH, Chen Z, Landy C and Hamdy RC: Dexamethasone induces caspase activation in murine osteoblastic MC3T3-E1 cells. Biochim Biophys Acta 1642: 79-85, 2003.
45. Li P, Nijhawan D, Budihardjo I, Srinivasula SM, Ahmad M, Alnemri ES and Wang X: Cytochrome $\mathrm{c}$ and dATP-dependent formation of Apaf-1/caspase-9 complex initiates an apoptotic protease cascade. Cell 91: 479-489, 1997.

46. Fischer U and Schulze-Osthoff K: New approaches and therapeutics targeting apoptosis in disease. Pharmacol Rev 57: 187-215, 2005.

47. Trapp T, Korhonen L, Besselmann M, Martinez R, Mercer EA and Lindholm D: Transgenic mice overexpressing XIAP in neurons show better outcome after transient cerebral ischemia. Mol Cell Neurosci 23: 302-313, 2003.

48. Riggs BL and Melton LJ III: The prevention and treatment of osteoporosis. N Engl J Med 327: 620-627, 1992.

49. Owen TA, Aronow M, Shalhoub V, Barone LM, Wilming L, Tassinari MS, Kennedy MB, Pockwinse S, Lian JB and Stein GS: Progressive development of the rat osteoblast phenotype in vitro: Reciprocal relationships in expression of genes associated with osteoblast proliferation and differentiation during formation of the bone extracellular matrix. J Cell Physiol 143: 420-430, 1990.

50. Huang W, Rudkin GH, Carlsen B, Ishida K, Ghasri P, Anvar B, Yamaguchi DT and Miller TA: Overexpression of BMP-2 modulates morphology, growth, and gene expression in osteoblastic cells. Exp Cell Res 274: 226-234, 2002.

51. Lee KS, Kim HJ, Li QL, Chi XZ, Ueta C, Komori T, Wozney JM, Kim EG, Choi JY, Ryoo HM and Bae SC: Runx2 is a common target of transforming growth factor betal and bone morphogenetic protein 2, and cooperation between Runx2 and Smad5 induces osteoblast-specific gene expression in the pluripotent mesenchymal precursor cell line C2C12. Mol Cell Biol 20: 8783-8792, 2000.

52. Gu H, Boonanantanasarn K, Kang M, Kim I, Woo KM, Ryoo HM and Baek JH: Morinda citrifolia leaf extract enhances osteogenic differentiation through activation of Wnt/beta-catenin signaling. J Med Food 21: 57-69, 2018.

53. Schaaf MJ and Cidlowski JA: Molecular determinants of glucocorticoid receptor mobility in living cells: The importance of ligand affinity. Mol Cell Biol 23: 1922-1934, 2003.

54. Maltese P, Canestrari E, Palma L, Ruzzo A, Corini F, Menotta M, Andreoni F, Latiano A, Annese V and Magnani M: High resolution melting (HRM) analysis for the detection of ER22/23EK, BclI, and N363S polymorphisms of the glucocorticoid receptor gene. J Steroid Biochem Mol Biol 113: 269-274, 2009.

55. De Bosscher K, Vanden Berghe W and Haegeman G: The interplay between the glucocorticoid receptor and nuclear factor-kappaB or activator protein-1: Molecular mechanisms for gene repression. Endocr Rev 24: 488-522, 2003.

56. Dostert A and Heinzel T: Negative glucocorticoid receptor response elements and their role in glucocorticoid action. Curr Pharm Des 10: 2807-2816, 2004.

57. Charmandari E, Kino T, Ichijo T and Chrousos GP: Generalized glucocorticoid resistance: Clinical aspects, molecular mechanisms, and implications of a rare genetic disorder. J Clin Endocrinol Metab 93: 1563-1572, 2008.

58. Blind RD and Garabedian MJ: Differential recruitment of glucocorticoid receptor phospho-isoforms to glucocorticoid-induced genes. J Steroid Biochem Mol Biol 109: 150-157, 2008.

59. Wang Z, Chen W, Kono E, Dang T and Garabedian MJ: Modulation of glucocorticoid receptor phosphorylation and transcriptional activity by a C-terminal-associated protein phosphatase. Mol Endocrinol 21: 625-634, 2007.

60. Woodbury R and Kligman AM: The hairless mouse model for assaying the atrophogenicity of topical corticosteroids. Acta Derm Venereol 72: 403-406, 1992.

(i) $(-)$ This work is licensed under a Creative Commons Attribution-NonCommercial-NoDerivatives 4.0 International (CC BY-NC-ND 4.0) License. 